\title{
Zusammenfassende Schlußbetrachtung
}

Die Arbeitskräfteplanung war ein immanenter und zentraler Bestandteil der Planwirtschaft in der SBZ/DDR. Der Übergang vom System der kriegsbedingten Zwangsbewirtschaftung zur Zentralverwaltungswirtschaft vollzog sich nicht geradlinig und nicht sofort nach Ende des Zweiten Weltkrieges. Es gab zwar schon frühzeitig einige Weichenstellungen, die prägenden Charakter für die ostdeutsche Wirtschaftsordnung hatten: Dazu zählten die Bodenreform, Sequestrierung und Beschlagnahmung von Bankguthaben sowie die sogenannte Industriereform, welche den schwerindustriellen Bereich der privaten Hand entzog und der staatlichen zuführte. Gleichwohl war damit nicht automatisch die Ausformung und Entwicklung des planwirtschaftlichen Systems verbunden, das sich erst im Verlauf der fünfziger Jahre zu einem komplexen und ausdifferenzierten Steuerungssystem entwickelte. Dieses stand im Mittelpunkt der vorliegenden Studie, die in Anlehnung an János Kornai in drei große Kapitel unterteilt wurde, die jeweils einen eigenen inhaltlichen Schwerpunkt besaßen. Im Mittelpunkt des ersten Kapitels stand die Bewältigung der unmittelbaren Kriegsfolgelasten für den Arbeitsmarkt und die beginnende Mobilisierung der Arbeitskräftereserven für die wirtschaftspolitischen Ziele von SMAD und SED. Kapitel zwei beschäftigte sich vor allem mit der fortgesetzten Arbeitskräftegewinnung und dem Erreichen eines Gleichgewichtszustandes. Im Verlauf des ersten Fünfjahrplanes hatte sich gezeigt, daß das zur Verfügung stehende Arbeitskräftepotential weitgehend ausgeschöpft und die Arbeitslosenrate nahezu bedeutungslos geworden war. Die Allokation des Produktionsfaktors, d.h. die bedarfsgerechte $\mathrm{Zu}$ - und Verteilung der Arbeitskräfte, war das zentrale Thema des dritten Kapitels. Die Schwächen der Planwirtschaft waren Mitte der fünfziger Jahre unübersehbar geworden. Nunmehr bestand für die Staatliche Plankommission und die Hegemonialpartei SED die vordringliche Aufgabe darin, Konzepte und Strategien zu entwickeln, um kurzfristig aufgetretene Defizite der zentralen Lenkung rechtzeitig zu erkennen und zu beseitigen.

Für die Arbeitskräfteplanung und -lenkung besaßen die Arbeitsämter eine zentrale Funktion. Diese Lenkungsinstanzen mußten nach Ende des Zweiten Weltkrieges teilweise wieder aufgebaut werden, was zum einen auf die einsetzende Entnazifizierung und zum anderen auf die wirtschaftspolitischen Ziele der Arbeiterparteien zurückzuführen war. Die Säuberung des öffentlichen Dienstes hatte zwar auch die Arbeitsverwaltung erfaßt, jedoch nicht zu solchen personalpolitischen Einschnitten geführt wie beispielsweise bei Polizei, Justiz, Lehrerschaft und Landesverwaltungen. Da die sowjetische Besatzungsmacht den personellen Aufbau der Arbeitsverwaltung sehr argwöhnisch beobachtete und regelmäßig eine Reduzierung der Personal- und Verwaltungskosten anmahnte, waren den Plänen der SED, große Lenkungsapparate zu errichten, enge Grenzen gesetzt. Hinzu kam, daß Moskau zwar frühzeitig den Aufbau von Zentralverwaltungen zugelassen hatte, diesen allerdings kaum Kompetenzen einräumen wollte. Dies hing vermutlich auch mit deutschlandpolitischen Überlegungen zusammen: Eine Einigung mit den drei westlichen Besatzungsmächten wurde bevorzugt und die Zentralisierung zunächst einmal gebremst. Davon profitierten wiederum die Landes- 
verwaltungen, die die Gestaltungsfreiräume zum Teil nutzen konnten. Über den strukturellen Aufbau der Arbeitsverwaltung entbrannte rasch eine Auseinandersetzung: Dabei mußte zwischen Kommunalisierung oder Zentralisierung entschieden werden. Die SMAD hatte zunächst allgemein eine Kommunalisierung favorisiert, während die SED eine Zentralisierung forderte, um die beginnende Wirtschaftsplanung institutionell abstützen zu können. Erst mit der Gründung der Deutschen Wirtschaftskommission (DWK) konnte diese Frage zugunsten der letzten Variante entschieden werden. Die SED-Führung hatte letztlich das überzeugende Argument auf ihrer Seite, daß eine bedarfsgerechte Planung und Lenkung der Arbeitskräfte einer zentralisierten Arbeitsverwaltung bedurfte. Vor allem die Kommunalverwaltungen, die sich vehement für eine Übernahme der Arbeitsämter ausgesprochen hatten, mußten somit eine Niederlage einstecken. Der bereits 1946 erfolgte dreigliedrige Aufbau mit der Deutschen Verwaltung für Arbeit und Sozialfürsorge (DVAS) an der Spitze führte nun zu einer zentralisierten Ausrichtung der Verwaltung, die zu Lasten der Landesverwaltungen ging.

Neben den institutionellen gab es in den ersten Nachkriegsjahren auch arbeitsrechtliche Weichenstellungen, die von entscheidender Bedeutung für die Arbeitskräftelenkung waren. Zentralen Stellenwert besaßen zunächst SMAD-Befehl Nr. 65 und Kontrollratsbefehl Nr. 3, die unter anderem die Arbeitseinweisung festschrieben. Diese Zwangsmaßnahme hing mit den Reparationsansprüchen der vier Siegermächte zusammen: Arbeitseinweisung gab es daher nicht nur in der SBZ, sondern auch in den drei westlichen Besatzungszonen. Während jedoch die Westmächte von diesem Instrument frühzeitig Abschied nahmen, blieb es in der SBZ auch weiterhin Bestandteil staatlicher Arbeitsmarktpolitik. Die zum Teil wilde Rekrutierungspraxis von sowjetischen Dienststellen in der SBZ konnte erst im Juni 1948 etwas eingedämmt werden: Die Verordnung über die Sicherung und den Schutz der Rechte bei Einweisungen von Arbeitskräften legte den Rahmen der Zwangseinweisung deutlich fest: So wurde etwa der zeitliche Umfang genau fixiert sowie eine Entschädigungszahlung und ein formelles Einspruchsrecht eingeführt. Diese Verordnung hatte bis 1954 Rechtsgültigkeit und war eine der wichtigsten arbeitsrechtlichen Bestimmungen. Aufgrund des Zwangscharakters dieser Maßnahme war die Nähe zur nationalsozialistischen Arbeitsmarktpolitik nicht von der Hand zu weisen. Darauf machten nicht nur betroffene Arbeiter, sondern auch Vertreter der SED-Führung und der Hauptverwaltung für Arbeit und Sozialfürsorge (HVAS) aufmerksam. In diesem Zusammenhang ist auch das Arbeitsbuch zu nennen, das Anfang 1947 wieder eingeführt wurde und der vollständigen Erfassung der erwerbstätigen Bevölkerung diente. Andere gesetzliche Bestimmungen wie das Gesetz zur Bekämpfung von Scheinselbständigkeit und die Verordnung über eine Erhebung zur Fluktuation, Arbeitsdisziplin und Leistung hatten eine unterstützende Funktion und sollten dazu beitragen, die erwerbsfähige Bevölkerung für den Arbeitsmarkt zu mobilisieren.

Angesichts der wirtschaftlichen und sozialen Folgen des Zweiten Weltkrieges stand die ostdeutsche Arbeitsverwaltung vor gewaltigen Aufgaben: Sie mußte unter anderem sowjetischen Reparationsforderungen nachkommen, die rückkehrenden Soldaten in die Arbeitswelt wieder eingliedern und die Flüchtlinge und Vertriebenen mit Arbeit versorgen. Die Registrierung der arbeitsfähigen und er- 
werbstätigen Bevölkerung verzögerte sich, so daß die DVAS in den ersten Nachkriegsmonaten noch keinen vollständigen Überblick über die Entwicklung auf dem Arbeitsmarkt besaß. Dennoch konnte eine systematische und regelmäßige Erfassung bereits im Frühjahr 1946 flächendeckend durchgeführt werden. Der rasche Rückgang der Arbeitslosenzahlen schien zunächst die Richtigkeit der von der DVAS eingeleiteten Maßnahmen zu bestätigen. Der erneute Anstieg der Arbeitslosenzahlen im Winter 1946/47 stellte nur eine kurze Episode dar; bis zum Sommer 1947 sanken diese nämlich auf ein Rekordtief und blieben bis zum Herbst 1948 auf niedrigem Niveau. Erst das unerwartete Ansteigen im Winter 1948/49 rief bei den politisch Verantwortlichen in den DWK-Hauptverwaltungen sowie bei der SED-Führung Beunruhigung hervor. Daraus wurde letztlich die Konsequenz gezogen, mit staatlichen Beschäftigungsprogrammen einzugreifen. Von der Arbeitslosigkeit waren von Anfang an die Frauen besonders betroffen: Sie wurden auf dem Arbeitsmarkt sukzessive verdrängt. Wirtschaftspolitische Programme der SED zur Förderung der Frauenbeschäftigung hatten oftmals nur propagandistische Wirkung. Hier zeigte sich auch die begrenzte Durchschlagskraft staatlicher Arbeitsmarktpolitik. So weigerten sich zahlreiche Betriebsleiter, Frauen einzustellen.

Der Rückgang der Arbeitslosenquote war auf mehrere Faktoren zurückzuführen. Die staatliche Arbeitskräftelenkung hatte daran zweifellos einen erheblichen Anteil: Es gehörte zu den Maximen der Arbeitsämter, Erwerbslose entsprechend ihrer beruflichen Qualifikation in Arbeit zu vermitteln. Wir haben allerdings bei der Darstellung der einzelnen Beschäftigungsprogramme sowie des zwischenund überbezirklichen Ausgleichs sehen können, daß diese interventionspolitische Maßnahme mit Folgeproblemen verknüpft war, die den Erfolg letztlich einschränkten. Daher ist es notwendig, weitere Faktoren in den Blick zu nehmen, die zum Anstieg der Beschäftigtenzahl und zum Absinken der Erwerbslosenzahlen beigetragen haben. Dazu gehörte vor allem, daß der Zugang zu Leistungen der Arbeitslosenversicherung und Sozialfürsorge erheblich erschwert wurde. Gleichzeitig weitete die HVAS jedoch die Arbeitseinsatzpflicht aus und verursachte mit dieser Maßnahme einen erneuten Anstieg der Arbeitslosenzahlen Ende 1948/Anfang 19491. Das verfassungsrechtlich festgelegte Recht auf Arbeit wurde somit frühzeitig mit einer Arbeitspflicht de facto verbunden, auch wenn die entsprechende Bestimmung erst 1961 Einzug in das Arbeitsrecht fand. Dahinter stand das Ziel, das Arbeitskräftepotential weitgehend auszuschöpfen und diejenigen in die Arbeitswelt zu zwingen, die bisher nicht erwerbstätig waren. Deshalb sollten unter anderem auch die Schwerbeschädigten beruflich integriert werden. Wie bei der propagierten Ausdehnung der Frauenerwerbstätigkeit zeigten sich jedoch auch hier die Grenzen der SED-Wirtschaftspolitik. Viele Kombinats- und Werksleiter versuchten die eingeführten Quoten zu umgehen. Da die SED und die Arbeitsverwaltung Sanktionsmittel in diesem Fall nicht einführten, blieb der Erfolg dieser arbeitsmarktpolitischen Maßnahme äußerst begrenzt.

Die Anforderungen der sowjetischen Besatzungsmacht schränkten den Handlungsspielraum der Arbeitsverwaltung von Anfang an erheblich ein. Die SMAD

1 Boldorf, Sozialfürsorge in der SBZ/DDR, S. 236. 
und die SMA in den Ländern und Provinzen, ja sogar einzelne sowjetische Dienststellen auf Kreisebene verlangten häufig von den Arbeitsämtern, Kontingente von Arbeitskräften für Demontagetätigkeiten oder für die Arbeit in den Sowjetischen Aktiengesellschaften (SAG) zusammenzustellen. Diese Form der Reparation geschah im einzelnen unkoordiniert, obwohl die Besatzungsmacht ihrerseits bemüht war, entsprechende Richtlinien herauszugeben und auch durchzusetzen, um dadurch die Tätigkeit der deutschen Arbeitsverwaltung zu erleichtern. Das gelang jedoch in den ersten beiden Nachkriegsjahren weitgehend nicht. In dem Zusammenhang ist zwischen kurz- und langfristigen Anforderungen zu unterscheiden. Langfristige Aufträge der sowjetischen Dienststellen hatten in der Regel eine mehrwöchige Laufzeit und konnten von den Arbeitsämtern oft erfüllt werden. Sehr viel schwieriger waren dagegen die kurzfristigen Forderungen, die innerhalb von wenigen Tagen zu erfüllen waren. Mit dieser Aufgabe war die deutsche Arbeitsverwaltung oftmals überfordert.

Bis zur DDR-Gründung bestand eine Hauptaufgabe der Arbeitsämter darin, Arbeitskräfte für den Uranbergbau im Erzgebirge bereitzustellen. Gerade in diesem Wirtschaftsbereich trug das Instrument der Zwangseinweisung, das von den Arbeitsämtern eingesetzt werden mußte, um den Anforderungen einigermaßen nachkommen zu können, zu einer erheblichen Verschlechterung der Stimmungslage der Belegschaften, aber auch der Gesamtbevölkerung bei. Die Kritik richtete sich rasch gegen die SMAD, die Sowjetunion und die SED, die frühzeitig als „Russenpartei“ abgestempelt wurde. Bei der Gegenüberstellung der Arbeitsvermittlungen und der Arbeitseinweisungen relativiert sich jedoch die Bedeutung dieser Zwangsmaßnahme. Für 1947 lassen sich wohl 9,8 Prozent aller Arbeitsvermittlungen als $Z$ wangseinweisung einstufen². Dabei entfiel ein Großteil der Zwangseinweisungen auf den Uranbergbau. Bereits 1947 setzte zunächst auf deutscher, später auch auf sowjetischer Seite ein Lernprozeß ein, der dazu führte, daß die Zwangseinweisung immer seltener praktiziert und statt dessen Anreize (Entlohnung, Wohnung, Lebensmittelversorgung) verstärkt zur Lenkung von Arbeitskräften in den Uranbergbau eingesetzt wurden. Einen qualitativen Wechsel brachte in dieser Frage erst der SMAD-Befehl Nr. 234, der langfristig gesehen den Wandel von den harten zu den weichen Maßnahmen einläutete. Die Einwände, die sowohl SED, FDGB als auch DVAS in Karlshorst ständig vorgetragen hatten, zeigten ihre Wirkung: Die sowjetische Besatzungsmacht verzichtete in zunehmendem Maße auf das Instrument der Zwangseinweisung. Hintergrund dafür bildete auch das übergeordnete Ziel, die Arbeitsproduktivität in den Betrieben zu erhöhen. Dies ließ sich nun auch aus Sicht der SMAD besser unter Einsatz von materiellen Anreizen realisieren. Nach den Vorstellungen der SMAD sollten unter anderem eine zusätzliche Lebensmittelversorgung eingeführt und die ärztliche Versorgung in den Betrieben verbessert werden. Die Differenzierung der Stückund Akkordlöhne diente zunächst einmal der Steigerung der Arbeitsproduktivität, hatte aber gleichzeitig eine Anreizfunktion für Arbeitsuchende.

Zwischen 1945 und 1949 wurden die wichtigsten Instrumente für die Arbeitskräftelenkung entwickelt und erprobt. Mit der Zwangseinweisung war der zwi-

2 Zank, Wirtschaft und Arbeit, S. 106. 
schen- und überbezirkliche Ausgleich eng verbunden. Dabei sollten nach den Vorstellungen der HVAS regionale Arbeitskräfteüberhänge rechtzeitig erkannt und zu einem Ausgleich gebracht werden. Dies konnte in der Frühphase auch durch die Arbeitseinweisung erfolgen. Doch auch hier zeigten sich schon bald die Mängel dieses Instruments: Die Motivation der zwangsweise verpflichteten Arbeitskräfte war oftmals nicht sonderlich hoch, wie die Arbeitsämter in ihren Berichten immer häufiger beklagten. Darüber hinaus setzte der zwischen- und überbezirkliche Ausgleich eine vollständige Kenntnis der Teilarbeitsmärkte mit den regionalen Sonderentwicklungen bei den Arbeitsämtern voraus, die in dem erhofften Maße kaum zu erreichen war. Erschwerend machte sich auch hier die unzureichende Wohnraumversorgung bemerkbar, die einer geplanten Umsetzung oft im Wege stand. Deshalb griff die Arbeitsverwaltung zu anderen Instrumenten, die jedoch stets mit der sowjetischen Besatzungsmacht abgestimmt werden mußten. Die geringsten Handlungsspielräume besaß die Arbeitsverwaltung bei der Lohnpolitik, die fast ausschließlich in den Händen der SMAD lag. Sie bestimmte letztlich die Erhöhung einzelner Löhne und Gehälter, wobei die deutschen Verwaltungen es durchaus verstanden, eigene Vorschläge einzubringen und die sowjetische Seite dafür zu gewinnen. Ein weiteres Steuerungsinstrument war der Wohnungsbau, der jedoch angesichts der Ausgangslage (z.T. hoher Zerstörungsgrad in den Städten und geringer finanzieller Spielraum) nur von nachrangiger Bedeutung sein konnte. Sehr viel wichtiger schien die Umschulung zu sein, die allmählich aufgebaut wurde. Sie war eine Reaktion auf die wachsende Zahl von Fehlvermittlungen, über die sich Betriebe und Arbeitsämter gleichermaßen beklagten. Für die spätere Entwicklung in den fünfziger Jahren waren jedoch die staatlichen Beschäftigungsprogramme entscheidend. Obwohl diese Programme das gesteckte Ziel nie erreichten, wurde hier doch der Grundstein für den ab 1950 erfolgenden Aufbau der Schwerindustrie gelegt. Der massive Auf- und Ausbau von Stahl- und Walzwerken, Betrieben der Eisenindustrie usw. erhöhte schlagartig die Nachfrage nach Arbeitskräften. Wesentliche Veränderungen vollzogen sich außerdem mit der Errichtung der Planwirtschaft, die langsam erfolgte. Dabei wurde die Arbeitskräfteplanung in die allgemeine Wirtschaftsplanung integriert.

Bei der Untersuchung der Instrumente, die in der SBZ zur Lenkung des Arbeitskräftepotentials eingesetzt wurden, stellt sich die Frage, inwieweit eine gruppenspezifische Arbeitsmarktpolitik festzustellen ist. Bei der großen Gruppe der „Umsiedler“, d.h. der Flüchtlinge und Vertriebenen, ist dies nur ansatzweise zu erkennen. Arbeitsmarktpolitische Maßnahmen, welche die Integration in die Arbeitswelt erleichtern sollten, gab es nur für kleine Personenkreise, so z.B. für die Handwerker des Gablonzer Kunsthandwerks, die in Thüringen wieder angesiedelt wurden. Ansonsten waren die Vertriebenen auf dem Arbeitsmarkt in der Regel sich selbst überlassen: Auch dort traten sie in Konkurrenz zu der einheimischen Bevölkerung und mußten oftmals Benachteiligungen in Kauf nehmen. Generell galt, daß die finanziellen Möglichkeiten der Landes- und Zentralverwaltungen zu sehr beschränkt waren, um kreditfinanzierte Beschäftigungsprogramme für einzelne soziale Gruppen durchführen zu können. Darüber hinaus sollte bei den „Umsiedlern“ ein politisches Sonderbewußtsein nicht gefördert werden, so $\mathrm{da} ß$ die SED-Führung und die Arbeitsverwaltung darauf verzichteten, entspre- 
chende Programme zu konzipieren und umzusetzen. Die Ambivalenz der arbeitsmarktpolitischen Maßnahmen für Frauen ist bereits erörtert worden. Größere Bedeutung gewann noch die Aus- und Weiterbildung von Jugendlichen. Mit Hilfe von sorgfältig angelegten Nachwuchsplänen sollte der effiziente Einsatz von ausgebildeten Jungfacharbeitern garantiert werden. Auch wenn die öffentliche Haushaltslage dem Vorhaben klare Grenzen setzte, so bedeutete dieser Schritt doch längerfristig eine qualitative Veränderung. Im Zuge der noch weiter zu entwikkelnden Wirtschaftsplanung nahm nämlich die Nachwuchsplanung einen eigenen Schwerpunkt ein. Für die Arbeitskräftelenkung war der Einsatz von Strafgefangenen letztlich bedeutungslos. Dieses Instrument, das sich im wesentlichen aus juristischen Reformbestrebungen speiste, ließ sich in der Praxis kaum anwenden. Aufgrund des Gefangenstatus war die Mobilität des ohnehin kleinen Personenkreises, der für diese Maßnahme in Frage kam, stark eingeschränkt.

Eine volkswirtschaftliche Gesamtplanung und -lenkung konnte in den ersten Nachkriegsjahren noch nicht stattfinden. Das ließ die sowjetische Besatzungsmacht zunächst noch nicht zu, wobei deutschlandpolitische Rücksichtnahmen vermutlich ein wesentliches Motiv waren. Darüber hinaus bedurfte die Errichtung der ostdeutschen Planwirtschaft - wie mehrmals erläutert - einer längeren Vorbereitungs- und Einarbeitungsphase. Vor dem Hintergrund der zunehmenden Bedeutung der Zentralverwaltungen sowie der SED als den maßgeblichen Akteuren bei der wirtschaftlichen Neuordnung erfolgte ungefähr ab 1948 der Übergang zur Zentralverwaltungswirtschaft. Einschneidende Stationen waren der Halbjahrplan 1948 sowie der Zweijahrplan 1949/50. Bereits 1947 war mit der Gründung der DWK eine mächtige Lenkungszentrale entstanden, die rasch an Bedeutung gewann und die de facto die Vorläuferin der DDR-Regierung war. Zwar hatten die deutschen Verwaltungen schon zuvor Monats- und Quartalsberichte über die wirtschaftliche Entwicklung in der SBZ zusammenstellen müssen. Diese waren jedoch ausschließlich für die SMAD bestimmt und besaßen in erster Linie Informationscharakter. Dabei übernahm die Arbeitsverwaltung in gewisser Weise eine Pionierfunktion: Bereits im Frühjahr 1946 hatte sie ein differenziertes Berichtsund Meldewesen entwickelt, auf das nunmehr zurückgegriffen werden konnte. Dabei wurde aber deutlich, daß die sich immer stärker herausbildende Planwirtschaft eine partielle Abkehr von der bisherigen Arbeitsmarktpolitik bedeutete: Aufgaben und Ziele der Arbeitsämter wurden nunmehr auf die übergeordneten Ziele der allgemeinen Wirtschaftsplanung ausgerichtet bzw. an diese Vorgaben angepaßt. Die Aufstellung des Zweijahrplanes bzw. des Fünfjahrplanes machte die Planung des Arbeitskräftepotentials zwangsläufig erforderlich. Arbeitskräfteplanung und -lenkung entwickelten sich so zu Teilbereichen der Wirtschaftspläne. Eine der wichtigsten Konsequenzen bestand darin, daß die gesonderte Beobachtung einzelner sozialer Gruppen durch die Arbeitsämter und die Staatliche Plankommission immer mehr vernachlässigt wurde und Mitte der fünfziger Jahre nahezu vollständig verschwand. Bereits 1949 war die gesonderte statistische Erfassung der "Umsiedler" aufgegeben worden, was im übrigen auch der politischen Linie der SED gegenüber dieser Gruppe entsprach.

Anfang der fünfziger Jahre begann auf Anweisung der SED-Führung und in enger Absprache mit der sowjetischen Besatzungsmacht der forcierte Auf- und 
Ausbau der Schwerindustrie. Während einzelne Stahl- und Walzwerke, wie das in Hennigsdorf, bereits vor 1945 bestanden hatten und wieder aufgebaut werden konnten, ging das Eisenhüttenkombinat Ost (EKO) auf den kompletten Neubau eines Industriestandortes zurück. Weil die dafür notwendige Infrastruktur erst noch aufgebaut werden mußte, wurden umgehend Investitionsmittel und Arbeitskräfte gezielt in diesen und andere neue schwerindustrielle Wirtschaftsstandorte gelenkt. Die zeitliche Verzögerung - das Programm begann nicht unmittelbar nach Kriegsende, sondern fünf Jahre später - erklärt sich zum Teil aus der Demontagepolitik der Sowjetunion, die zunächst ihre Reparationsziele verfolgte. Eine weitere Ursache war die beginnende Teilung Deutschlands: Mit der Gründung der DDR und der bereits vorher beginnenden politischen und wirtschaftlichen Trennung der vier Besatzungszonen sowie ihrer Einbindung in zwei konträre Blocksysteme setzte sich bei den politisch Verantwortlichen in der SBZ/ DDR immer mehr die Vorstellung durch, die ostdeutsche Wirtschaft von Zulieferungen aus dem Westen unabhängig machen zu wollen. Darüber hinaus schien der Aufbau einer eigenen Schwerindustrie als Anschub für den ökonomischen Aufbau des Landes unabdingbar zu sein. Und schließlich wies das sowjetische Vorbild in eine gleiche wirtschaftspolitische Richtung.

Der schnelle Aufbau der Schwerindustrie zog eine hohe Nachfrage nach ausgebildeten Facharbeitern sowie nach an- und ungelerntem Personal nach sich. Dabei war vor allem die Rekrutierung von qualifizierten Fachkräften problematisch, da diese in der ursprünglich vorgesehenen Zahl noch nicht zur Verfügung standen. Somit mußten Facharbeiter erst noch ausgebildet werden, während der Bedarf an an- und ungelernten Arbeitskräften rascher befriedigt werden konnte. Deshalb entwickelte sich die Facharbeiterausbildung zu einem zentralen Aufgabenbereich der zuständigen Verwaltungen. SED-Führung und Arbeitsministerium mußten nämlich befürchten, daß die im Rahmen des Fünfjahrplans aufgestellten Produktionsziele andernfalls nicht zu erfüllen waren. Schnelle Erfolge konnten jedoch nicht erwartet werden. Hinzu kam, daß sich die einzelnen Stahl- und Walzwerke nicht in der Lage sahen, die eigene Lehrlingsausbildung erheblich zu vergrößern, da hierfür wiederum zusätzliche Lehrkräfte, Verwaltungspersonal und Sachmittel benötigt wurden. Somit erfolgte die Berufsausbildung teilweise am Bedarf vorbei. Dies hing wiederum auch mit der ständig wachsenden und sich verändernden Nachfrage nach ausgebildetem Fachpersonal sowie den Ausbildungszeiten zusammen.

Neben der Nachwuchsförderung gewann auch die Lohnpolitik weiter an Bedeutung. In den fünfziger Jahren waren dies die beiden wichtigsten Instrumente der Arbeitskräftelenkung. Bei der Festsetzung der Löhne ergab sich eine Reihe von Folgeproblemen, die vom Arbeitsministerium berücksichtigt werden mußten. So hatte etwa der mit dem SMAD-Befehl Nr. 234 eingeführte Leistungslohn in der volkseigenen Industrie eine Überarbeitung des gesamten Lohngefüges nach sich gezogen. Die SED befand sich in dem Dilemma, daß sie auf der einen Seite eine Besserstellung der unteren Einkommensgruppen und damit eine Angleichung der Löhne propagierte, auf der anderen Seite aber eine Differenzierung der Löhne betreiben mußte, um das Ziel einer Steigerung der Arbeitsproduktivität zu verwirklichen. Letztlich sollten aber die Löhne nach den Vorstellungen der SED- 
Führung und des Ministerrates in unregelmäßigen Abständen der Produktivitätsentwicklung angepaßt werden. Aufgrund der angespannten Haushaltslage trat in dieser Angelegenheit das Finanzministerium häufig als Kritiker auf und konnte oftmals übereilte lohnpolitische Maßnahmen blockieren. Oberste Priorität genossen Arbeiter der Schwerindustrie, die in der Regel als erste in den Genuß von Lohnerhöhungen kamen. Es kann festgehalten werden, daß in der SBZ/DDR Löhne, die von der SED und der Staatlichen Plankommission zentral festgelegt wurden, nicht nur die Funktion hatten, zur Produktivitätssteigerung in den Betrieben beizutragen, sondern nach wie vor eine wenn auch eingeschränkte marktregulierende Aufgabe wahrnahmen. Mit anderen Worten: Löhne behielten auch weiterhin ihre Anreizfunktion innerhalb des planwirtschaftlichen Systems.

Einige institutionelle Veränderungen zu Beginn der fünfziger Jahre wirkten sich nachteilig auf die Entwicklung der Arbeitskräfteplanung und -lenkung aus. Als erstes ist die Auflösung der Arbeitsämter zu nennen, die auf der Verordnung vom 12. Juli 1951 über die Aufgaben der Arbeitsverwaltungen und über die Lenkung der Arbeitskräfte basierte. In Anlehnung an das sowjetische Vorbild sollten zukünftig die Industrieministerien für die Steuerung der Arbeitskräfte zuständig sein. Es konnte nachgewiesen werden, daß die sowjetische Besatzungsmacht in diesem Punkt ihren Einfluß geltend machte und die Neuordnung dieses Verwaltungszweiges durchsetzte. In der Folgezeit wurden bei den Bezirksverwaltungen Abteilungen für Arbeit und Berufsausbildung gebildet, die einen Teil der Aufgaben wahrnehmen sollten, die zuvor von den Arbeitsämtern ausgefüllt worden waren. Mit der Verordnung vom 12. Juli 1951 verabschiedete sich die DDR von einer eigenständigen Arbeitsverwaltung, die seit dem Ende des 19. Jahrhunderts ein fester Bestandteil der deutschen öffentlichen Verwaltung gewesen war. Daneben gewann eine weitere Entwicklung an Bedeutung: Mit der Auflösung der Länder und der Bildung der Bezirke im Sommer 1952 wurde die Kommunalverwaltung noch stärker in die Arbeitskräftelenkung einbezogen. Das sollte aus Sicht der SED und der Staatlichen Plankommission die Effektivität der Planung erhöhen, führte aber andererseits auch dazu, daß sich etwa der zwischenbezirkliche Ausgleich von Arbeitskräften schwieriger gestaltete, da nunmehr die Städte und Kreise die ihnen zugewiesenen Aufgaben mitunter dazu nutzten, ihre eigenen Interessen und Ziele zu verfolgen.

Weitaus wichtiger wurde jedoch die Zusammenarbeit zwischen Arbeitsverwaltung und Staatlicher Plankommission, die etwa seit Mitte der fünfziger Jahre für die Aufstellung der Arbeitskräftepläne zunehmend relevanter wurde. Die Aufgaben des 1958 aufgelösten Ministeriums für Arbeit und Berufsausbildung übernahmen in der Folgezeit die Staatliche Plankommission und das Komitee für Arbeit und Löhne. Auch das Komitee für Arbeit und Löhne, das von Februar 1958 bis Mai 1963 existierte, wurde mehrmals umstrukturiert und gelangte rasch in den Zuständigkeitsbereich der Staatlichen Plankommission, wo es letztlich auch verblieb. Völlig neuartigen Charakter besaß die Staatliche Plankommission, die Ende 1950 errichtet wurde und die Aufgaben übernahm, die zuvor die Hauptverwaltung Wirtschaftsplanung bzw. das Ministerium für Planung wahrgenommen hatten. Damit entstand eine Einrichtung, die sukzessive Aufgaben zugewiesen bekam, die bisher im Zuständigkeitsbereich einzelner Fachministerien gelegen hat- 
ten. Diese zentrale institutionelle Weichenstellung, die sich bereits vor 1949 abgezeichnet hatte, hing eng mit der Entscheidung zusammen, die Volkswirtschaft zentral zu planen und zu steuern. Bereits im Frühjahr 1951 war die Staatliche Plankommission zuständig für die Planung der Investitionen, Arbeitskräfte und Warenzirkulation in den Wirtschaftsbereichen Industrie, Landwirtschaft, Verkehr, Kultur und Gesundheitswesen. Auch wenn sich die Staatliche Plankommission rasch als oberste Planungsbehörde etablieren konnte, so blieben doch Konflikte mit den jeweiligen Fachministerien nicht aus. Einzelne Forscher stellten noch jüngst das Institutionengefüge der DDR-Planwirtschaft als klar hierarchisch gegliedertes und aufeinander abgestimmtes System dar ${ }^{3}$. Dieser Interpretation kann in der vorliegenden Studie nicht gefolgt werden. Die SED-Führung beanspruchte zwar in allen Politikbereichen die oberste Entscheidungsbefugnis, sie überließ es aber häufig den untergeordneten Verwaltungen, Problemlösungen auszuarbeiten. Dabei mußten beispielsweise die Fachministerien oftmals einen Konsens untereinander herstellen, da Politbüro und Sekretariat des ZK Entscheidungen verschoben oder diesen aus dem Weg gingen. Diese Verwaltungspraxis erinnert daher eher an polykratische Strukturen, wie sie für das nationalsozialistische Regime bereits frühzeitig herausgearbeitet worden sind ${ }^{4}$. In der SBZ/DDR bestand somit keine in sich geschlossene und klar aufeinander abgestimmte Zentralverwaltungswirtschaft.

Während es dem Arbeitsministerium und der Kommunalverwaltung in den ersten Jahren nach der DDR-Gründung noch einigermaßen gelungen war, den Bedarf an Arbeitskräften insgesamt abzudecken, zeichneten sich seit Mitte der fünfziger Jahre immer größere Schwierigkeiten bei der Arbeitskräfteplanung und -lenkung ab. Die beteiligten Ressorts und Verwaltungen mußten zur Kenntnis nehmen, daß die vorausschauende Bedarfsplanung unzureichend gewesen war. Dies lag zum einen an der „Republikflucht“, die erhebliche Auswirkungen auf die Struktur der Erwerbsbevölkerung hatte. SED-Führung, Staatliche Plankommission und Arbeitsministerium befanden sich in dieser Frage von Anfang an in der Defensive: Sie mußten auf das unkalkulierbare und unberechenbare Massenphänomen reagieren - bis zum Mauerbau kehrten mindestens 2,75 Millionen Menschen der DDR den Rücken - und etwa den Verlust an Facharbeitern in einzelnen Wirtschaftsbranchen auszugleichen versuchen. Eine langfristige Planung des Arbeitskräfteeinsatzes war angesichts der stetigen Abwanderung in den Westen Deutschlands nicht durchführbar. Alle eingeleiteten Gegenmaßnahmen der Staats- und Parteiführung konnten diese Entwicklung, die unter anderem mit einem Legitimationsverlust des neuen Staates und der Hegemonialpartei verbunden war, nicht aufhalten. Erst mit dem Mauerbau 1961 wurde der bis dahin noch über Berlin ungehinderte Zugang in die Bundesrepublik radikal unterbunden. Der Arbeitskräftemangel in einzelnen Wirtschaftszweigen hing zum anderen mit systemimmanenten Schwächen zusammen. So machte sich in Teilen der Schwerindustrie ein Arbeitskräfteüberhang bemerkbar. Entlassungen standen unmittelbar bevor

3 Schroeder, Der SED-Staat, S. 489-502.

4 Vgl. Broszat, Der Staat Hitlers; Frei, Der Führerstaat; Hüttenberger, Nationalsozialistische Polykratie. 
und stellten die kommunalen und zentralen Verwaltungen vor eine ungewohnte und unerwartete Aufgabe, glaubte man doch zu diesem Zeitpunkt, die Arbeitslosigkeit endgültig überwunden zu haben. Zur gleichen Zeit registrierte das Arbeitsministerium einen Mangel an Arbeitskräften in der Landwirtschaft, da diese Jahre zuvor in die Industrie gelenkt worden waren. Die staatlichen Behörden waren nunmehr mit den Unzulänglichkeiten ihres eigenen Planungs- und Lenkungssystems konfrontiert. Der Rückgang der Beschäftigtenzahlen im Uranbergbau vergrößerte den Druck auf die kommunalen Abteilungen Arbeit und Berufsausbildung, die sich hilfesuchend an die SED-Führung und die Staatliche Plankommission in Berlin wandten. Den entlassenen Arbeitern mußten kurzfristig neue Arbeitsplätze angeboten werden. Diese Aufgabe konnte erst über einen längeren Zeitraum hinweg befriedigend gelöst werden.

Angesichts dieser sich zuspitzenden Rahmenbedingungen war es nicht weiter verwunderlich, daß das Arbeitsministerium und die Staatliche Plankommission 1956/57 Überlegungen anstellten, die Instrumente der Arbeitskräftelenkung zu überprüfen und die Verordnung vom 12. Juli 1951 grundlegend zu überarbeiten. Dabei verfolgten die beteiligten Stellen das Ziel, die Kompetenzen der einzelnen Planungsinstanzen auf zentraler, regionaler und lokaler Ebene besser aufeinander abzustimmen und zu einer Arbeitseinweisung zurückzukehren. Hintergrund dafür bildete auch die Fluktuation von Arbeitskräften zwischen den einzelnen Betrieben, die von staatlicher Seite kaum gesteuert werden konnte. Auch wenn diese Planungen letztlich nur theoretische Überlegungen beinhalteten und keinerlei praktische arbeitsrechtliche Konsequenzen hatten, sind sie zunächst einmal als Indiz für eine gewisse Ratlosigkeit zu werten, die sich vor allem auf seiten der Staatlichen Plankommission ausgebreitet hatte, und implizierten das Eingeständnis der Erfolglosigkeit der bisher eingeleiteten Maßnahmen. Die zwischen der SED-Führung, dem Ministerium für Arbeit und Berufsausbildung, dem Komitee für Arbeit und Löhne und der Staatlichen Plankommission geführte Debatte erstreckte sich nicht nur auf den möglichen Neuaufbau einer eigenständigen Arbeitsverwaltung, wie sie bis zur Auflösung der Arbeitsämter 1951 bestanden hatte, sondern drehte sich generell um die Aufgaben und Ziele einer zentralen Arbeitskräftelenkung. Für die Wiedereinführung einer Arbeitseinweisung, die jedoch an das Einverständnis der Betroffenen gekoppelt wurde, plädierte nur das Komitee für Arbeit und Löhne. Vor allem der stellvertretende Vorsitzende des Ministerrates Heinrich Rau wandte sich gegen diesen Vorschlag und konnte sich damit innerhalb des DDR-Ministerrates und der SED-Führung durchsetzen. Beide befürchteten offenbar eine Verschlechterung der Stimmungslage in der Bevölkerung und ein Ansteigen der Flüchtlingszahlen. Deshalb wurde die Verabschiedung der geplanten Verordnung zur Reorganisation der Arbeitskräftelenkung vorerst zurückgestellt. Rund zwei Wochen nach dem Mauerbau erfolgte die Verabschiedung der Verordnung zur Verbesserung der Arbeitskräftelenkung und Berufsberatung, welche die seit 1951 in die Bedeutungslosigkeit abgesunkene Arbeitsverwaltung wieder aufwertete. Damit wurden außerdem Arbeitskräftelenkung und Berufsberatung institutionell miteinander verbunden. Dagegen waren die anfänglichen Pläne zur Wiedereinführung einer begrenzten Arbeitseinweisung vollständig fallengelassen worden. 
Die Arbeitskräftelenkung erfolgte nicht nur durch bürokratische Koordinierung, sondern auch durch Instrumente, die marktkoordinierende Funktionen besaßen. Damit bestätigt sich die Vermutung Kornais, der von einem Mischsystem ausgegangen war, das in sozialistischen Wirtschaftssystemen Steuerungsaufgaben wahrnimmt ${ }^{5}$. Von entscheidender Bedeutung ist allerdings in einem weiteren Schritt, die einzelnen Instrumente in ihrer Bedeutung und im Zeitverlauf zu gewichten. Wir haben gesehen, daß die Lohnpolitik anfangs von der Besatzungsmacht nahezu alleine festgelegt wurde. Doch bereits in dieser Phase ist erkennbar, daß die vorgenommenen Lohn- und Gehaltserhöhungen mit den wirtschaftspolitischen Leitideen korrespondierten, die eben eine Bevorzugung der Schwerindustrie vorsahen. Die Lohnpolitik gewann in den fünfziger Jahren zunehmend an Bedeutung und hatte auch noch andere Aufgaben zu erfüllen. So sollten die Löhne und Gehälter produktivitätsorientiert gestaltet werden und letztlich zu einer Steigerung der Arbeitsproduktivität beitragen. Während die Lohnpolitik in der Frühphase das Ziel verfolgte, Arbeiter in die rasch aufzubauenden Schwerpunktbetriebe zu locken, änderte sich dies ab Mitte der fünfziger Jahre. Nunmehr ging es darum, Stammbelegschaften zu bilden und die Arbeiter an ihren Betrieb zu binden. Die Wohnungsbaupolitik stellte ein anderes Hauptinstrument dar. Angesichts des allgemeinen Wohnraummangels schien der massive Ausbau von Wohnstädten in unmittelbarer Nähe zu Kombinaten und Großbetrieben eine Anreizfunktion zu besitzen. Finanzierungsschwierigkeiten, Material- und Bauarbeitermangel verzögerten jedoch häufig den Bauabschluß und trugen dazu bei, daß dem Wohnungsbau nicht die von der SED erhoffte Rolle zukam. Ein langfristig angelegtes Instrument zur Arbeitskräftelenkung war außerdem die Berufsberatung und -ausbildung. Der Facharbeitermangel in einzelnen Wirtschaftszweigen sollte auf diese Weise behoben werden. Doch auch hier machte sich eine zeitliche Verzögerung bemerkbar: Eine bedarfsgerechte Ausbildung war letztlich nicht vollständig zu realisieren, da sich der Bedarf kurzzeitig ändern konnte und die langen Ausbildungszeiten eine rasche Bedarfsdeckung unmöglich machten. Was für die Arbeitskräfteplanung und -lenkung generell galt, traf somit auch für die Berufsausbildung zu: Die beteiligten Ministerien und Verwaltungen standen vor der fast unlösbaren Aufgabe, mit dem richtigen Arbeitskräftebestand zum richtigen Zeitpunkt am richtigen Ort zu sein. Mit dem ersten Fünfjahrplan wuchsen die bürokratischen Koordinierungsinstrumente. Den einzelnen Fachministerien und den Vereinigungen Volkseigener Betriebe wurde der jeweilige Arbeitskräftebestand zentral vorgegeben, der wiederum durch Eingaben einzelner Betriebe revidiert werden konnte. Insofern mußte die dafür letztlich verantwortliche Staatliche Plankommission eine gewisse Flexibilität an den Tag legen. Gleichwohl änderte sich im Untersuchungszeitraum kaum etwas Wesentliches an der prinzipiellen Bevorzugung des schwerindustriellen Sektors bei der Zuteilung von Arbeitskräften. Dagegen blieb die Leicht- und Konsumgüterindustrie von nachrangiger Bedeutung; dies galt ebenso für den privaten Wirtschaftssektor.

Bei den Entscheidungen der SED-Führung, die in nahezu allen Sachfragen die absolute Kompetenz allein für sich reklamierte, vermischten sich oftmals ökono-

5 Kornai, Das sozialistische System, S. 255. 
mische und politische Motive. Das hatte zwangsläufig Auswirkungen auf die Arbeitskräftelenkung in der DDR: Im Rahmen des ersten Fünfjahrplanes wurde der Schwerpunkt bei der Zuteilung von Investitionsmitteln und Arbeitskräften eindeutig auf den Ausbau der Schwerindustrie gelegt. Diese Prioritätensetzung wurde stets beibehalten. Die Folgen dieser einseitigen Allokation sollten etwa bei der Aktion „Industriearbeiter aufs Land" ausgeglichen werden, die zugleich mit einem weiteren Ziel verknüpft wurde: der gewünschten Stärkung der Landwirtschaftlichen Produktionsgenossenschaften. Für die SED-Führung waren somit wirtschaftliche und ideologische Ziele eng miteinander verbunden; eine Trennung zwischen beiden Bereichen mit dem Ziel der Verbesserung des Steuerungssystems schien nicht möglich zu sein. Vorsichtige Ansätze zu einer Wirtschaftsreform während der sechziger Jahre, die den Betrieben mehr Handlungsspielraum zugestehen sollte, scheiterten auch daran, daß sich für die Hegemonialpartei SED damit die Machtfrage stellté.

Bei der Analyse der DDR-Zentralverwaltungswirtschaft bietet sich ein Vergleich mit der NS-Wirtschaftspolitik an, der nicht im Zentrum der vorliegenden Studie lag und an dieser Stelle auch nicht nachgeholt werden soll. Es seien dennoch einige Randbemerkungen erlaubt, da in der wissenschaftlichen Debatte in den letzten Jahre mitunter allzu leichtfertige und vorschnelle Synopsen vorgenommen wurden 7 . In enger Anlehnung an Überlegungen Walter Euckens gelangten etwa Jürgen Schneider und Wolfgang Harbrecht zum Ergebnis, daß die „nationalsozialistische, marktlose, gelenkte Wirtschaft [...] in der Sowjetisch besetzten Zone (SBZ)/DDR zur markt- und unternehmerlosen sozialistischen Zentralplanwirtschaft nach sowjetischem Modell ausgebaut" wurde8. Diese primär ordnungstheoretische Betrachtungsweise ist sehr holzschnittartig und der historischen Entwicklung in der SBZ/DDR nicht ganz angemessen. Am Beispiel der Arbeitskräftelenkung konnte nachgewiesen werden, daß die Zentralverwaltungswirtschaft keineswegs unmittelbar nach Kriegsende vollständig aufgebaut werden konnte und im Sinne der SED-Führung sofort funktionstüchtig war. Darüber hinaus liegt dieser Interpretation implizit ein Sowjetisierungsmodell zugrunde, welches deutsche Handlungsspielräume fast unberücksichtigt läßt und von der historischen Forschung in letzter Zeit zunehmend in Frage gestellt wird ${ }^{9}$. Zweifellos gab es Gemeinsamkeiten zwischen der Arbeitsmarktpolitik im Dritten Reich und in der SBZ/DDR. Zahlreiche Instrumente wie beispielsweise das Arbeitsbuch, die Lohnfestsetzung oder die Arbeitseinweisung lassen sich in beiden Diktaturen finden. Die Entscheidung zugunsten einer zentralen Steuerung des Arbeitsmarktes, die während der nationalsozialistischen Herrschaft vor allem kriegsbedingt erfolgte und funktionalen Charakter besaß, zog die erwähnten Maßnahmen nahezu automatisch nach sich. Von ausschlaggebender Bedeutung für eine vergleichende Beurteilung ist jedoch der jeweilige historische Kontext. Dieser beeinflußte unter anderem die weitere Entwicklung und den Stellenwert der Lenkungsinstrumente.

6 Vgl. Steiner, Die DDR-Wirtschaftsreform.

7 Vgl. Schneider/Harbrecht, Einführung: Wirtschaftspolitische Experimente im Laboratorium

Kriegswirtschaft/Weimar/Drittes Reich (1914-1948) und in Sowjetrußland (ab i917).

8 Ebenda, S. XLIII.

9 Vgl. Jarausch/Siegrist, Amerikanisierung und Sowjetisierung in Deutschland 1945-1970. 
So beseitigten etwa die nationalsozialistischen Machthaber nicht die private Verfügungsgewalt über die Produktionsfaktoren. Die NS-Kriegswirtschaft organisierte in der Phase des "Totalen Krieges" $z$ war eine nahezu vollständige Verteilung der knappen Ressourcen. Insgesamt kann aber von einer zum Teil engen Kooperation von politischer Führung und Industrieunternehmern ausgegangen werden ${ }^{10}$. In der SBZ/DDR ist dagegen eine ganz andere Entwicklung zu beobachten: Hier wurden frühzeitig Schlüsselindustrien enteignet und verstaatlicht. Im $\mathrm{Zu}$ sammenhang mit der Bodenreform, der Sequestrierung und der Beschlagnahmung von Bankguthaben wurde das freie Unternehmertum schon frühzeitig ausgeschaltet, auch wenn sich in einzelnen Wirtschaftszweigen - z. B. beim Handwerk - private Betriebe bis Anfang der siebziger Jahre halten konnten. Durch die Kollektivierung Ende der fünfziger bzw. Anfang der sechziger Jahre wurde auch in der Landwirtschaft die private Eigentumsform weitgehend zurückgedrängt. Darüber hinaus hatte das NS-Regime während des Zweiten Weltkriegs auf ein riesiges Arbeitskräftereservoir zurückgegriffen, um den Arbeitskräftebedarf für die Kriegsführung zu befriedigen: die Fremdarbeiter'11. In der vorliegenden Studie konnte gezeigt werden, daß die DDR erst nach dem Mauerbau sehr zaghaft versuchte, ausländische Arbeitskräfte aus den „befreundeten Staaten“ zu gewinnen. Die Beschäftigung ausländischer Arbeiter setzte jedoch erst einige Jahre später ein und erreichte zu keinem Zeitpunkt eine herausragende Bedeutung ${ }^{12}$. Somit werden grundlegende Unterschiede deutlich, die zumindest einen bruchlosen Übergang von der NS-Kriegswirtschaft zur ostdeutschen Zentralverwaltungswirtschaft in Frage stellen.

10 Frei, Der Führerstaat, S. 90-92; Petzina, Autarkiepolitik, S. 196-198.

11 Im August 1944 befanden sich 7,65 Millionen ausländische Arbeitskräfte $(26,5 \%$ der Gesamtbeschäftigten) im "Großdeutschen Reich“, darunter 1,9 Millionen Kriegsgefangene. Herbert, Fremdarbeiter, S. 270.

12 Die Ausländerquote betrug in der DDR 1989 1,1\% (191000 Personen). Elsner/Elsner, Ausländer und Ausländerpolitik in der DDR, S. 5. 


\section{Verzeichnis der Tabellen und Grafiken}

Grafik 1: Entwicklung der Arbeitslosigkeit in der SBZ

(ohne Berlin) 1945-1949 (in Tausend)

Tabelle 1: Entwicklung der Arbeitslosigkeit in der SBZ (ohne Berlin) 1945-1949 (in Tausend) . . . . . . . . . . . 109

Tabelle 2: Zahl der Arbeitspflichtigen in der SBZ (ohne Berlin), die keine Arbeit suchen, 1947-1949 (in Tausend) . ........ 110

Tabelle 3: Arbeitslosigkeit von Frauen in der SBZ (ohne Berlin)

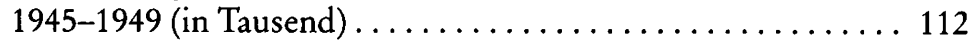

Tabelle 4: Zahl der erwerbsbeschränkten Arbeitslosen in der SBZ (ohne Berlin) 1946-1949 (in Tausend) . . . . . . . . . . . . . 113

Tabelle 5: Zahl der offenen Stellen in der SBZ (ohne Berlin) 1946-1949 (in Tausend) . . . . . . . . . 114

Grafik 2: Entwicklung der Arbeitslosigkeit in der DDR 1950-1955 (in Tausend) .......................... 270

Tabelle 6: Entwicklung der Arbeitslosigkeit in der DDR 1950-1955 (in Tausend) ............................. 271

Tabelle 7: Arbeitslosigkeit von Frauen in der DDR 1950-1955

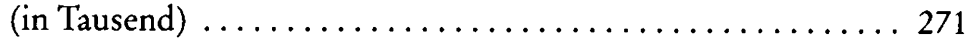

Tabelle 8: Arbeitslosigkeit von Jugendlichen unter $18 \mathrm{Jahren}$ in der DDR 1950-1955 (in Tausend) .

Tabelle 9: Zahl der erwerbsbeschränkten Arbeitslosen in der DDR 1950/51 (in Tausend)..................... 272

Tabelle 10: Zahl der offenen Stellen in der DDR 1950-1953 (in Tausend) . 274

Tabelle 11: Erfüllung der Auflagen für die Wismut AG 1952......... 347

Tabelle 12: Bereitstellung von Arbeitskräften für die Wismut AG durch die Bezirke November 1952-August 1953 ......... 348

Tabelle 13: Übersicht über die unselbständig Beschäftigten im Bergbau 1949/50............................ 352

Tabelle 14: Belegschaftswechsel über das Arbeitsamt im Steinkohlenrevier Zwickau 1950.................. 352

Tabelle 15: Stand der Arbeitskräftewerbung im Kombinat Mansfeld (1. Halbjahr 1952) ........................... 361

Tabelle 16: Arbeiter in den einzelnen Lohngruppen im Bereich der Hauptverwaltung Kohle A. Steinkohle ............ 384

Tabelle 17: Arbeiter in den einzelnen Lohngruppen im Bereich der Hauptverwaltung Kohle B. Braunkohle . . . . . . . . . . . . 384

Tabelle 18: Zusammenstellung der auf die einzelnen Berufsgruppen entfallenden Lehrlinge im Nachwuchsplan 1950 (Planzahlen)

Tabelle 19: prozentualer Anteil der Frauen an der Gesamtzahl der unselbständig Beschäftigten nach Berufsordnungen und -gruppen ............................... 409 
Tabelle 20: Frauenanteil (in Prozent) in einzelnen Lohngruppen (III. Quartal 1952) ........................... 412

Tabelle 21 a: Übersicht über die Beschäftigungslage unter Jugendlichen (Stand: 31. Oktober 1950)..................... 414

Tabelle 21 b: Übersicht über die Beschäftigungslage unter Jugendlichen (Stand: 31. Oktober 1950)...................... 414

Tabelle 22: Überblick über die Zahl der auslernenden Jugendlichen (Stand: Mai 1953) ........................ 422

Tabelle 23: Rückgang der Beschäftigtenzahlen in einzelnen Bereichen der Schwerindustrie 1954/55 .................. 436

Tabelle 24: Rückgang der Beschäftigtenzahlen in einzelnen Bereichen der Schwerindustrie 1955/56 (in Tausend). . . . . . . . . 437

Tabelle 25: Geplante Entlassungen in der Schwerindustrie 1955 ...... 445

Tabelle 26: Entwicklung der Beschäftigung in einzelnen Wirtschaftsbereichen 1950-1955 (in Tausend)........... 449

Tabelle 27: Beschäftigte nach sozialen Gruppen 1950-1955 (in Tausend) . . 450

Tabelle 28: Einkommensverteilung bei den Arbeitern und Angestellten Mitte 1956, ohne Halbtagskräfte, Lehrlinge und Heimarbeiter (in Tausend) .......................... 457

Tabelle 29: Übersicht über die Entwicklung der „Republikflucht“ im Bereich des Ministeriums für Berg- und Hüttenwesen (1955/56-1957)....

Tabelle 30: Überhänge an "Jungfacharbeitern" im Zuständigkeitsbereich der einzelnen Fachministerien und Staatssekretariaten (Herbst 1953) .......................... 507

Tabelle 31: Entwicklung der Berufsausbildung 1950-1954 (in Tausend) . . 510 Tabelle 32: Entwicklung des Arbeitskräftebestandes in den Betrieben der HV Stein- und Braunkohle (1955/56) . . . . . . . . . 524 


\section{Abkürzungen}

Abt.

ABUS

ACDP

ADL

AfS

AG

AK

APUZ

AVAVG

AVP RF

BAB

Bd.

Bl.

BLHA

$\mathrm{BStU}$

$\mathrm{BzG}$

CDU

ČSR

DA

DAF

DDR

DFD

DJV

DM

DVAS

DVdI

DWK

EKO

FDGB

FDJ

GG

GOSPLAN

Abteilung

Ausrüstung von Bergbau und Schwerindustrie

Archiv für Christlich-Demokratische Politik, St. Augustin

Archiv des Deutschen Liberalismus, Gummersbach

Archiv für Sozialgeschichte

Aktiengesellschaft

Arbeitskräfte

Aus Politik und Zeitgeschichte

Gesetz über Arbeitsvermittlung und Arbeitslosenversicherung

Archiw wneschnei politiki Rossijskoi Federazii, Moskau

Bundesarchiv, Berlin-Lichterfelde

Band

Blatt

Brandenburgisches Landeshauptarchiv, Potsdam-Bornim

Der Bundesbeauftragte für die Unterlagen des Staatssicherheitsdienstes der ehemaligen DDR

Beiträge zur Geschichte der Arbeiterbewegung

Christlich-Demokratische Union

Tschechoslowakische Republik

Deutschland Archiv

Deutsche Arbeitsfront

Deutsche Demokratische Republik

Demokratischer Frauenbund Deutschlands

Deutsche Zentralverwaltung für Justiz

Deutsche Mark (DM Ost)

Deutsche Verwaltung für Arbeit und Sozialfürsorge

Deutsche Verwaltung des Innern

Deutsche Wirtschaftskommission

Eisenhüttenkombinat Ost

Freier Deutscher Gewerkschaftsbund

Freie Deutsche Jugend

Geschichte und Gesellschaft

Gosudarstwennaja Planowaja Komissija (Staatliche Plankommission)

HA

Hauptabteilung 


\section{HV Hauptverwaltung}

HVAS Hauptverwaltung Arbeit und Sozialfürsorge

HVDVP Hauptverwaltung Deutsche Volkspolizei

$\mathrm{HZ}$

Historische Zeitschrift

IG

IHK

Industriegewerkschaft

IWK

Kap.

Industrie- und Handelskammer

Internationale Wissenschaftliche Korrespondenz zur Ge-

schichte der Arbeiterbewegung

$\mathrm{KPD}$

Kapitel

LA

LAA

Landesarchiv

$\mathrm{LDP}(\mathrm{D})$

Landesarbeitsamt

LHA

Liberal-Demokratische Partei (Deutschlands)

LPG

Landeshauptarchiv

Landwirtschaftliche Produktionsgenossenschaft

MAS

Maschinen-Ausleih-Station

MdI

Ministerium des Innern

MTS

MW

Maschinen-Traktoren-Station

Ministerium für Wirtschaft

NATO

North Atlantic Treaty Organization

NDPD

$\mathrm{Nr}$.

National-Demokratische Partei Deutschlands

NS

Nummer

NSDAP

Nationalsozialismus

ÖLB

Örtlich geleiteter Landwirtschaftsbetrieb

Rep.

Repertorium

RGW

Rat für gegenseitige Wirtschaftshilfe

RM

Reichsmark

SächsHStA Sächsisches Hauptstaatsarchiv, Dresden

SAG

SAPMO Stiftung Archiv der Parteien und Massenorganisationen der

Sowjetische Aktiengesellschaft

SBZ

SDAG

SED

DDR im Bundesarchiv

SKK

Sowjetische Besatzungszone

Sowjetisch-Deutsche Aktiengesellschaft

Sozialistische Einheitspartei Deutschlands

SMA

Sowjetische Kontrollkommission

SMAD

Sowjetische Militäradministration

Sowjetische Militäradministration in Deutschland 
SPD

SPK

TH

ThHStA

UdSSR

$\mathrm{Vdg} B$

$\mathrm{VdN}$

VEB

VEG

$\mathrm{VfZ}$

VR

VSWG

VVB

ZA

ZfG

ZK

ZKSK

ZS

ZVAS

ZVU
Sozialdemokratische Partei Deutschlands

Staatliche Plankommission

Technische Hochschule

Thüringisches Hauptstaatsarchiv, Weimar

Union der Sozialistischen Sowjetrepubliken

Vereinigung der gegenseitigen Bauernhilfe

Verfolgter des Naziregimes

Volkseigener Betrieb

Volkseigenes Gut

Vierteljahrshefte für Zeitgeschichte

Volksrepublik

Vierteljahrschrift für Sozial- und Wirtschaftsgeschichte

Vereinigung Volkseigener Betriebe

Zentralarchiv

Zeitschrift für Geschichtswissenschaft

Zentralkomitee

Zentrale Kommission für Staatliche Kontrolle

Zentralsekretariat

Zentralverwaltung für Arbeit und Sozialfürsorge

Zentralverwaltung für deutsche Umsiedler 


\title{
Quellen- und Literaturverzeichnis
}

\author{
A. Ungedruckte Quellen \\ Stiftung Archiv der Parteien und Massenorganisationen der DDR \\ im Bundesarchiv, Berlin (SAPMO)
}

\begin{tabular}{|c|c|}
\hline$R Y$ & $K P D$ \\
\hline $1 / \mathrm{I} 1 / 1$ & Parteitage der KPD \\
\hline $1 / \mathrm{I} 1 / 2$ & Parteikonferenzen der KPD \\
\hline $1 / \mathrm{I} 2 / 2$ & Zentrale/ZK \\
\hline $1 / \mathrm{I} 2 / 5$ & Sekretariat des ZK der KPD \\
\hline $1 / \mathrm{I} 3 / 1-2$ & KPD-Bezirk Berlin-Brandenburg-Lausitz-Grenzmark \\
\hline $1 / \mathrm{I} 3 / 8-10$ & KPD-Bezirk Sachsen \\
\hline $1 / \mathrm{I} 3 / 12$ & KPD-Bezirk Magdeburg/Anhalt \\
\hline $1 / \mathrm{I} 3 / 13$ & KPD-Bezirk Thüringen \\
\hline $1 / \mathrm{I} 3 / 11$ & KPD-Bezirk Halle-Merseburg \\
\hline$D Y 28$ & SPD nach 1945 \\
\hline II 1 & Parteitage und -konferenzen \\
\hline II 2 & SPD-Zentralausschuß \\
\hline DY 29 & Aktionsgemeinschaft KPD/SPD \\
\hline III $70-83$ & Aktions- und Arbeitsgemeinschaft KPD/SPD 1945/46 \\
\hline$D Y 30$ & $S E D$ \\
\hline IV $2 / 2.1$ & Protokolle des Zentralsekretariats (1946-1949) \\
\hline IV $2 / 2$ & Protokolle des Politbüros (1949-1953) \\
\hline $\mathrm{J}$ IV $2 / 2$ & Protokolle des Politbüros (1953-1965) \\
\hline $\mathrm{J}$ IV $2 / 2 \mathrm{~A}$ & Arbeitsprotokolle des Politbüros (1953-1965) \\
\hline J IV $2 / 3$ & Protokolle des Sekretariats des ZK (1949-1965) \\
\hline J IV $2 / 3 \mathrm{~A}$ & Arbeitsprotokolle des Sekretariats des ZK (1949-1965) \\
\hline IV $2 / 2.027$ & ZK-Abteilung Gewerkschaften und Sozialpolitik \\
\hline IV $2 / 6.11$ & ZK-Abteilung Gewerkschaften und Sozialpolitik \\
\hline IV $2 / 2.022$ & Teilbestand Sekretariat Paul Merker \\
\hline IV $2 / 2.029$ & Büro Erich Apel und Wirtschaftskommission beim Politbüro 1951-1962 \\
\hline IV $2 / 2.101$ & Wirtschaftskommission beim Politbüro des ZK \\
\hline IV $2 / 6.02$ & ZK-Abteilung Wirtschaftspolitik \\
\hline IV $2 / 6.03$ & Abteilung Grundstoffindustrie \\
\hline IV 2/6.04 & Abteilung Maschinenbau und Metallurgie \\
\hline IV $2 / 9.05$ & ZK-Abteilung Volksbildung \\
\hline IV $2 / 13$ & ZK-Abteilung Staat und Recht \\
\hline IV $2 / 16$ & ZK-Abteilung Jugend \\
\hline IV $2 / 17$ & ZK-Abteilung Frauen \\
\hline J IV 2/201 & Büro Walter Ulbricht \\
\hline J IV $2 / 202$ & Büro Walter Ulbricht \\
\hline $\mathrm{J}$ IV $2 / 2 \mathrm{~J}$ & Berichte und Informationen an das Politbüro \\
\hline $\mathrm{J}$ IV $2 / 3 \mathrm{~J}$ & Berichte und Informationen an das Sekretariat des ZK \\
\hline$N Y$ & Nachlässe \\
\hline 4017 & laß Martha Arendsee \\
\hline
\end{tabular}


4036

4076

4090

4182

4405

4406

4409

4421

4473

4495

Nachlaß Wilhelm Pieck

Nachlässe Hermann und Jenny Matern

Nachlaß Otto Grotewohl

Nachlaß Walter Ulbricht

Nachlaß Roman Chwalek

Nachlaß Adolf Deter

Nachlaß Bernhard Göring

Nachlaß Grete Groh-Kummerlöw

Nachlaß Helmut Lehmann

DY 34

Nachlaß Friedel Malter

Tagung des Bundesvorstandes

Sekretariat des FDGB-Bundesvorstandes (1948-1962)

Büro des Präsidiums

Präsidiumssitzungen (1952-1965)

Vorstandssekretariat (1946-1949)

Büro Herbert Warnke

Büro Bernhard Göring

Büro Alexander Starck

Büro Otto Lehmann

Büro Zöllner

Hauptabteilung I (Organisation; 1945-1949)

Hauptabteilung II (Wirtschaftspolitik)

Hauptabteilung III (Sozialpolitik)

Abteilung Organisation (ab 1950)

Abteilung Arbeit und Löhne (1950-1960)

Büros der Sekretäre für Arbeit und Löhne

Abteilung Sozialpolitik (ab 1950)

Abteilung Recht

Betriebsräte

DY 37 IG Bergbau

DY $46 \quad$ IG Metall

DY $52 \quad$ ZVIG Wismut

\section{Bundesarchiv, Berlin-Lichterfelde (BAB)}

DC 15

DC 20

DC $20 \mathrm{I} / 3$

DC $20 \mathrm{I} / 4$

DC 20/Ulbricht

DE 1

DG 2

DO $1 / 7$

DO $1 / 8$

DO $1 / 11$

DO 2

DQ 2

DQ 3
Deutsche Wirtschaftskommission

Ministerrat

Sitzungen und Beschlüsse des Ministerrates

Präsidium des Ministerrates

Ministerrat, Teilbestand Ulbricht

Staatliche Plankommission

Ministerium für Schwerindustrie

Ministerium des Innern, Deutsche Verwaltung des Innern

Ministerium des Innern, örtliche Räte

Ministerium des Innern, Hauptverwaltung Deutsche Volkspolizei

Zentralverwaltung für deutsche Umsiedler

Ministerium für Arbeit und Berufsausbildung

Staatssekretariat für Arbeit und Löhne 
Bundesarchiv, Archivdepot Coswig

DC 1 Zentrale Kommission für Staatliche Kontrolle

DE $4 \quad$ Volkswirtschaftsrat

Brandenburgisches Landeshauptarchiv, Potsdam-Bornim (BLHA)

Ld. Br. Rep. 202 A Büro des Ministerpräsidenten

Ld. Br. Rep. 206 Wirtschaftsministerium

Ld. Br. Rep. 250 Landratsämter

Ld. Br. Rep. 271 VVB Land Brandenburg

Ld. Br. Rep. 330 KPD-Bezirksleitung 1945/46

Ld. Br. Rep. 331 SPD-Bezirksvorstand 1945/46

Ld. Br. Rep. 332 SED-Landesvorstand Brandenburg

Ld. Br. Rep. 333 Aktionsgemeinschaft KPD/SPD 1945/46

Ld. Br. Rep. 502 VEB Walzwerk Kirchmöser

Ld. Br. Rep. 502 Stahl- und Walzwerk Hennigsdorf

Ld. Br. Rep. 502 VEB Stahl- und Walzwerk Brandenburg (Abgabe 1985 und 1986)

Ld. Br. Rep. 547 FDGB-Landesvorstand

Ld. Br. Rep. 903 VEB Synthesewerk Schwarzheide

Rep. 270

Rep. 530

Rep. 901

VVB (Z) Welzow

Bezirk Potsdam

VVB Braunkohle, Sitz Senftenberg

Rep. 901

VEB Braunkohlenwerk Plessa

\section{Landesarchiv Magdeburg-Landeshauptarchiv (LAM-LHA)}

Rep. K Minpräs Büro des Ministerpräsidenten

Rep. K MW Ministerium für Wirtschaft und Verkehr

Rep. K MdF Ministerium der Finanzen

Rep. K MdI Ministerium des Innern

Rep. K Bezirksverwaltung Magdeburg

Rep. K Industriewerke Sachsen-Anhalt

Direktorat der Kohlenindustrie Sachsen-Anhalt

Braunkohlenverwaltung Magdeburg, VVB der Kohlenindustrie

VEB Bergbau- und Hüttenkombinat Calbe (Saale)

VEB Kupfer- und Blechwalzwerk „Michael Niederkirchner“ Ilsenburg

FDGB-Landesvorstand Sachsen-Anhalt

\section{Sächsisches Hauptstaatsarchiv, Dresden}

Landesregierung Sachsen, Ministerpräsident

Landesregierung Sachsen, Ministerium für Arbeit und Sozialfürsorge

Landesregierung Sachsen, Ministerium für Wirtschaft und Arbeit (Landesplanung)

Landesregierung Sachsen, Ministerium für Wirtschaft

Bezirkstag/Rat des Bezirkes Dresden

Steinkohlenwerk Zauckerode

Gesellschaft Gießerei-Industrie Sachsen, Johanngeorgenstadt

VEB Steinkohlenwerk „Willi Agatz“ Freital

VEB Steinkohlenverwaltung $Z$ wickau

Kaliindustrie

KPD-Bezirksleitung Sachsen 
SPD-Landesvorstand Sachsen

Aktions- und Arbeitsgemeinschaft von KPD und SPD

SED-Landesleitung Sachsen

SED-Bezirksleitung Dresden

FDGB-Landesvorstand Sachsen

\section{Thüringisches Hauptstaatsarchiv, Weimar}

Land Thüringen, Büro des Ministerpräsidenten

Der Ministerpräsident, HA Wirtschaftsplanung

Land Thüringen, Ministerium für Wirtschaft und Arbeit

Rheinmetall Borsig, SAG Sömmerda

VEB Kombinat Kali

VVB Mineral und Erze

$\mathrm{I} / 1$

II $/ 1$

III

IV
KPD 1945/46

SPD 1945/46

Aktionseinheit KPD/SPD

SED-Landesleitung

Archiv für Christlich-Demokratische Politik, St. Augustin (ACDP)

$\mathrm{VII} / 10$

$\mathrm{VII} / 11$

$\mathrm{VII} / 12$

$\mathrm{VII} / 13$

III/31

III $/ 35$
Vorstand

Sekretariat des Hauptvorstandes

Parteiarbeit

Sachthemen

LV Thüringen

LV Sachsen

\section{Archiv des Deutschen Liberalismus, Gummersbach (ADL)}

Protokolle des Zentralvorstandes

Protokolle des Hauptausschusses

Protokolle des Politischen Ausschusses des Zentralvorstandes

Protokolle des Sekretariats des Zentralvorstandes

Sekretariat des Vorsitzenden

Ausschuß für Sozialpolitik

Landesverband Brandenburg, Landesvorstand

Landesverband Sachsen, Landesvorstand

Landesverband Sachsen-Anhalt, Landesvorstand

Landesverband Thüringen, Landesvorstand

\section{Der Bundesbeauftragte für die Unterlagen des Staatssicherbeitsdienstes der ehemaligen DDR, (BStU), Zentralarchiv (ZA), Berlin}

Dokumentenstelle (DSt)

Juristische Hochschule des MfS (JHS)

Kader und Schulung (KuSch/KS)

Sekretariat des Ministers (SdM)

Zentrale Arbeitsgruppe Geheimnisschutz (ZAGG)

Zentrale Auswertungs- und Informationsgruppe (ZAIG) 


\section{Archiw wneschnei politiki Rossijskoi Federazii, Moskau (AVP RF)}

Fonds 458 , opis 3

Fonds 458, opis 72

\section{B. Gedruckte Quellen}

Akten zur Vorgeschichte der Bundesrepublik Deutschland 1945-1949. Bd. 4: Januar-Dezember 1948, bearb. von Christoph Weisz/Hans-Dieter Kreikamp/Bernd Steger, München 1983.

Amtsblatt des Kontrollrats in Deutschland, hrsg. vom Alliierten Sekretariat, Berlin o.J.

Die Arbeit. Theoretische Zeitschrift des Freien Deutschen Gewerkschaftsbundes, o.O. $1947 \mathrm{ff}$.

Arbeit und Sozialfürsorge, Berlin (Ost) $1946 \mathrm{ff}$.

Die neue Arbeitsgerichtsbarkeit, Berlin 1947.

Befehle des Obersten Chefs der Sowjetischen Militärverwaltung in Deutschland. Aus dem Stab der Sowjetischen Militärverwaltung in Deutschland, Sammelheft 1 und 2, Berlin 1946.

Berichte der Landes- und Provinzialverwaltungen zur antifaschistisch-demokratischen Umwälzung 1945/46. Quellenedition, Berlin (Ost) 1989.

Bonwetsch, Bernd/Bordjugov, Gennadij/Naimark, Norman M. (Hrsg.): Sowjetische Politik in der SBZ 1945-1949. Dokumente zur Tätigkeit der Propagandaverwaltung (Informationsverwaltung) der SMAD unter Sergej Tjul'panov, Bonn 1998.

Buddrus, Michael: „... im Allgemeinen ohne besondere Vorkommnisse“. Dokumente zur Situation des Strafvollzugs der DDR nach der Auflösung der sowjetischen Internierungslager 1949-1951, in: DA 29 (1996), S. 10-33.

Conelly, John: Zur „Republikflucht“ von DDR-Wissenschaftlern in den fünfziger Jahren, in: ZfG 42 (1994), S. 331-352.

Dokumente der Sozialistischen Einheitspartei Deutschlands, Bd. I ff., Berlin (Ost) $1952 \mathrm{ff}$.

Dokumente zur Geschichte der kommunistischen Bewegung in Deutschland. Reihe 1945/ 1946. Hrsg. von Günter Benser und Hans-Joachim Krusch. Bd. 3: Protokoll der Reichsberatung der KPD 8./9. Januar 1946, bearb. von Günter Benser und Hans-Joachim Krusch, München u.a. 1995.

Eckelmann, Wolfgang/Hertle, Hans-Hermann/Weinert, Rainer: FDGB intern. Innenansichten einer Massenorganisation der SED, Berlin 1990.

Einheitsdrang oder Zwangsvereinigung? Die Sechziger Konferenzen von KPD und SPD 1945 und 1946. Mit einer Einführung von Hans-Joachim Krusch und Andreas Malycha, Berlin 1990.

Engelmann, Roger/Schumann, Silke: Der Ausbau des Überwachungsstaates. Der Konflikt Ulbricht-Wollweber und die Neuausrichtung des Staatssicherheitsdienstes der DDR 1957, in: VfZ 43 (1995), S. 341-378.

Entnazifizierung. Politische Säuberung und Rehabilitierung in den vier Besatzungszonen 1945-1949, hrsg. von Clemens Vollnhals, München 1991.

Foitzik, Jan: Berichte des Hohen Kommissars der UdSSR in Deutschland aus den Jahren 1953/54. Dokumente aus dem Archiv für Außenpolitik der Russischen Föderation, in: Materialien der Enquete-Kommission „Aufarbeitung von Geschichte und Folgen der SED-Diktatur in Deutschland“, hrsg. vom Deutschen Bundestag, Bd. II/2, Baden-Baden/ Frankfurt am Main 1995, S. 1350-1541. 
Ders.: „Hart und konsequent ist der neue politische Kurs zu realisieren“. Ein Dokument zur Politik der Sowjetunion gegenüber der DDR nach Berijas Verhaftung im Juni 1953, in: DA 33 (2000), S. 32-49.

Vorstand des FDGB (Hrsg.): Geschäftsbericht des Freien Deutschen Gewerkschaftsbundes 1946, Berlin (Ost) 1947.

Bundesvorstand des FDGB (Hrsg.): Aus der Arbeit des Freien Deutschen Gewerkschaftsbundes 1947-1949, Berlin (Ost) 1950.

Ders. (Hrsg.): Geschäftsbericht des Bundesvorstandes des FDGB zum 4. FDGB-Kongreß 1950-1954, Berlin (Ost) o.J.

Ders. (Hrsg.): Rechenschaftsbericht des Bundesvorstandes an den 5. FDGB-Kongreß 19551959, Berlin (Ost) o.J.

Gesetzblatt der Deutschen Demokratischen Republik 1949ff., Berlin (Ost) $1949 \mathrm{ff}$.

"Gruppe Ulbricht" in Berlin, April bis Juni 1945. Von den Vorbereitungen im Sommer 1944 bis zur Wiederbegründung der KPD im Juni 1945. Eine Dokumentation. Mit einem Geleitwort von Wolfgang Leonhard, hrsg. und eingel. von Gerhard Keiderling, Berlin 1993.

Gniffke, Erich W.: Jahre mit Ulbricht, Köln 1966.

Herrnstadt, Rudolf: Das Herrnstadt-Dokument. Das Politbüro der SED und die Geschichte des 17. Juni 1953, hrsg. von Nadja Stulz-Herrnstadt, Hamburg 1990.

Hoffmann, Dierk/Schmidt, Karl-Heinz/Skyba, Peter (Hrsg.): Die DDR vor dem Mauerbau. Dokumente zur Geschichte des anderen deutschen Staates 1949-1961, München/Zürich 1993.

Judt, Matthias (Hrsg.): DDR-Geschichte in Dokumenten. Beschlüsse, Berichte, interne Materialien und Alltagszeugnisse, Berlin 1997.

Kranig, Andreas: Arbeitsrecht im NS-Staat. Texte und Dokumente, Köln 1984.

Malycha, Andreas: Auf dem Weg zur SED. Die Sozialdemokratie und die Bildung einer Einheitspartei in den Ländern der SBZ - Eine Quellenedition, Bonn 1995.

Neuaufbau der deutschen Wirtschaft. Richtlinien der KPD zur Wirtschaftspolitik, Berlin 1946.

Pieck, Wilhelm: Aufzeichnungen zur Deutschlandpolitik 1945-1953, hrsg. von Rolf Badstübner/Wilfried Loth, Berlin 1993.

Potsdam 1945. Quellen zur Konferenz der „Großen Drei“, hrsg. von Ernst Deuerlein, München 1963.

Protokoll der Verhandlungen des II. Parteitages der Sozialistischen Einheitspartei Deutschlands, 20. bis 24. September 1947, Berlin (Ost) 1947.

Protokoll des III. Parteitages der Sozialistischen Einheitspartei Deutschlands, 20. bis 24. Juli 1950, Berlin (Ost) 1951.

Protokoll der Verhandlungen des IV. Parteitages der Sozialistischen Einheitspartei Deutschlands, 30. März bis 6. April 1954, Berlin (Ost) 1954.

Protokoll des V. Parteitages der Sozialistischen Einheitspartei Deutschlands, 10. bis 16. Juli 1958, Berlin (Ost) 1959.

Protokoll der 1. Parteikonferenz der Sozialistischen Einheitspartei Deutschlands, 25. bis 28. Januar 1949, Berlin (Ost) 1949.

Protokoll der II. Parteikonferenz der Sozialistischen Einheitspartei Deutschlands, 9. bis 12. Juli 1952, Berlin (Ost) 1952.

Protokoll der Verhandlungen der III. Parteikonferenz der Sozialistischen Einheitspartei Deutschlands, 24. bis 30. März 1956, Berlin (Ost) 1956.

Protokolle der Provisorischen Volkskammer, 1949/50.

Protokolle der Volkskammer der Deutschen Demokratischen Republik, $1951 \mathrm{ff}$. 
Scherstjanoi, Elke: „Wollen wir den Sozialismus?“. Dokumente aus der Sitzung des Politbüros des ZK der SED am 6. Juni 1953, in: BzG 33 (1991), S. 658-680.

Dies.: Die sowjetische Deutschlandpolitik nach Stalins Tod 1953. Neue Dokumente aus dem Archiv des Moskauer Außenministeriums, in: VfZ 46 (1998), S. 497-549.

Schollwer, Wolfgang: Potsdamer Tagebuch 1948-1950. Liberale Politik unter sowjetischer Besatzung, hrsg. von Monika Faßbender, München 1988.

Selbmann, Fritz: Planung und Wirtschaftspolitik, Dresden 1947.

Ders.: Volksbetriebe im Wirtschaftsplan, Berlin 1948.

Ders.: Für eine gesamtdeutsche Wirtschaftspolitik, Berlin (Ost) 1949.

Das SKK-Statut. Zur Geschichte der Sowjetischen Kontrollkommission in Deutschland 1949 bis 1953. Eine Dokumentation. Im Auftrag des Instituts für Zeitgeschichte zusammengestellt und eingeleitet von Elke Scherstjanoi, München 1998.

Staritz, Dietrich: Die SED, Stalin und die Gründung der DDR. Aus den Akten des Zentralen Parteiarchivs des Instituts für Geschichte der Arbeiterbewegung (ehemals Institut für Marxismus-Leninismus beim ZK der SED), in: APUZ B 5/91, S. 3-16.

Ders.: Stalin und der "Aufbau des Sozialismus“ in der DDR. Aus den Akten des Zentralen Parteiarchivs, in: DA 24 (1991), S. 686-700.

Statistisches Jahrbuch der Deutschen Demokratischen Republik, Berlin (Ost) $1955 \mathrm{ff}$.

Steiner, André: Politische Vorstellungen und ökonomische Probleme im Vorfeld der Errichtung der Berliner Mauer. Briefe Walter Ulbrichts an Nikita Chruschtschow, in: Hartmut Mehringer (Hrsg.): Von der SBZ zur DDR, München 1995, S. 233-268.

Stöckigt, Rolf: Ein Dokument von großer historischer Bedeutung vom Mai 1953, in: BzG 32 (1990), S. 648-654.

Suckut, Siegfried: Blockpolitik in der SBZ/DDR 1945-1949. Die Sitzungsprotokolle des zentralen Einheitsfront-Ausschusses. Eine Quellenedition, Köln 1986.

Ders.: Die Entscheidung zur Gründung der DDR. Die Protokolle der Beratungen des SEDParteivorstandes am 4. und 9. Oktober 1949, in: VfZ 39 (1991), S. 125-175.

Ulbricht, Walter: Unsere Wirtschaftspolitik 1949. Referat und Schlußwort auf der Ersten Parteikonferenz der SED, Berlin (Ost) 1949.

Vergleich von Bildung und Erziehung in der Bundesrepublik Deutschland und in der Deutschen Demokratischen Republik (=Materialien zur Lage der Nation, hrsg. vom Bundesministerium für innerdeutsche Beziehungen), wissenschaftl. Leitung: Oskar Anweiler, Köln 1990.

Volksrichter in der SBZ/DDR 1945 bis 1952. Eine Dokumentation, hrsg. u. eingel. von Hermann Wentker, München 1997.

Weber, Hermann (Hrsg.): Parteiensystem zwischen Demokratie und Volksdemokratie. Dokumente und Materialien zum Funktionswandel der Parteien und Massenorganisationen in der SBZ/DDR 1945-1950, Köln 1982.

Ders.: DDR. Dokumente zur Geschichte der Deutschen Demokratischen Republik 19451985, München 1986.

Wengst, Udo: Der Aufstand am 17. Juni 1953 in der DDR. Aus den Stimmungsberichten der Kreis- und Bezirksverbände der Ost-CDU im Juni und Juli 1953, in: VfZ 41 (1993), S. 277-321.

Der Wirtschaftsplan 1949/50. Wiederherstellung und Entwicklung der Friedenswirtschaft in der sowjetischen Besatzungszone, Berlin (Ost) 1948.

Wolkow, Wladimir K.: Die deutsche Frage aus Stalins Sicht (1947-1952), in: ZfG 48 (2000), S. 20-49.

Zentralverordnungsblatt, Jahrgang 1947, hrsg. namens aller Zentralverwaltungen von der 
Deutschen Justizverwaltung der sowjetischen Besatzungszone in Deutschland, Berlin 1947.

Zentralverordnungsblatt. Amtliches Organ der Deutschen Wirtschaftskommission und ihrer Hauptverwaltungen sowie der Deutschen Verwaltungen für Gesundheitswesen, Inneres, Justiz und Volksbildung, Jahrgang 1948, hrsg. von der Deutschen Justizverwaltung der sowjetischen Besatzungszone in Deutschland, Berlin 1948.

Zentralverordnungsblatt. Amtliches Organ der Deutschen Wirtschaftskommission und ihrer Hauptverwaltungen sowie der Deutschen Verwaltungen für Inneres, Justiz und Volksbildung, Jahrgang 1949, hrsg. von der Deutschen Justizverwaltung der sowjetischen Besatzungszone in Deutschland, Berlin 1949. 


\section{Literatur}

Abelshauser, Werner: Wirtschaft in Westdeutschland 1945-1948. Rekonstruktion und Wachstumsbedingungen in der amerikanischen und britischen Zone, Stuttgart 1975.

Ders.: Wirtschaftsgeschichte der Bundesrepublik Deutschland (1945-1980), Frankfurt am Main 1983.

Ders.: Der Ruhrkohlenbergbau seit 1945. Wiederaufbau, Krise, Anpassung, München 1984.

Ders. (Hrsg.): Die Weimarer Republik als Wohlfahrtsstaat. Zum Verhältnis von Wirtschaftsund Sozialpolitik in der Industriegesellschaft, Stuttgart 1987.

Ders.: Kriegswirtschaft und Wirtschaftswunder. Deutschlands wirtschaftliche Mobilisierung für den Zweiten Weltkrieg und die Folgen für die Nachkriegszeit, in: VfZ 47 (1999), S. 503-538.

Altrichter, Helmut: Die Bauern von Tver. Vom Leben auf dem russischen Dorfe zwischen Revolution und Kollektivierung, München 1984.

Ambrosius, Gerold: Funktionswandel und Strukturveränderung der Bürokratie 1945-1949: Das Beispiel der Wirtschaftsverwaltung, in: Politische Weichenstellungen im Nachkriegsdeutschland 1945-1953, hrsg. von Heinrich August Winkler, Göttingen 1979, S. 167-207.

Ders.: Der Beitrag der Vertriebenen und Flüchtlinge zum Wachstum der westdeutschen Wirtschaft nach dem Zweiten Weltkrieg, in: Jahrbuch für Wirtschaftsgeschichte 1996/2, S. 39-71.

Anatomie der Staatssicherheit. Geschichte, Struktur und Methoden. MfS-Handbuch, hrsg. von Siegfried Suckut/Clemens Vollnhals/Walter Süß/Roger Engelmann. Die Hauptabteilung XVIII: Volkswirtschaft, bearb. von Maria Haendcke-Hoppe-Arndt, Berlin 1997.

Arbeitslosigkeit in der Arbeitsgesellschaft. Hrsg. von Wolfgang Bonß und Rolf G. Heinze, Frankfurt am Main 1984.

Baar, Lothar/Karlsch, Rainer/Matschke, Werner: Kriegsschäden, Demontagen und Reparationen, in: Materialien der Enquete-Kommission „Aufarbeitung von Geschichte und Folgen der SED-Diktatur in Deutschland“, hrsg. vom Deutschen Bundestag, Bd. II/2, Baden-Baden/Frankfurt am Main 1995, S. 868-988.

Ders./Müller, Uwe/Zschaler, Frank: Strukturveränderungen und Wachstumsschwankungen. Investitionen und Budget in der DDR 1949 bis 1989, in: Jahrbuch für Wirtschaftsgeschichte 1995/2, S. 47-74.

Ders./Petzina, Dietmar (Hrsg.): Deutsch-Deutsche Wirtschaft 1945 bis 1990. Strukturveränderungen, Innovationen und regionaler Wandel. Ein Vergleich, St. Katherinen 1999.

Bähr, Johannes: Entstehung und Folgen des Arbeitsgerichtsgesetzes von 1926. Zum Verhältnis von Arbeiterschaft, Arbeiterbewegung und Justiz zwischen Kaiserreich und Nationalsozialismus, in: Arbeiter im 20. Jahrhundert, hrsg. von Klaus Tenfelde, Stuttgart 1991, S. 507-532.

Ders.: Institutionenordnung und Wirtschaftsentwicklung. Die Wirtschaftsgeschichte der DDR aus der Sicht des zwischendeutschen Vergleichs, in: GG 25 (1999), S. 530-555.

Ders./Petzina, Dietmar (Hrsg.): Innovationsverhalten und Entscheidungsstrukturen. Vergleichende Studien zur wirtschaftlichen Entwicklung im geteilten Deutschland 19451990, Berlin 1996.

Bajohr, Stefan: Weiblicher Arbeitsdienst im „Dritten Reich“. Ein Konflikt zwischen Ideologie und Ökonomie, in: VfZ 28 (1980), S. 331-357.

Barthel, Horst: Die wirtschaftlichen Ausgangsbedingungen der DDR. Zur Wirtschaftsentwicklung auf dem Gebiet der DDR 1945-1949/50, Berlin (Ost) 1979. 
Bauerkämper, Arnd: Von der Bodenreform zur Kollektivierung. Zum Wandel der ländlichen Gesellschaft in der Sowjetischen Besatzungszone Deutschlands und DDR 1945-1952, in: Hartmut Kaelble/Jürgen Kocka/Hartmut Zwahr (Hrsg.): Sozialgeschichte der DDR, Stuttgart 1994, S. 119-143.

Ders. (Hrsg.): „Junkerland in Bauernhand“? Durchführung, Auswirkungen und Stellenwert der Bodenreform in der Sowjetischen Besatzungszone, Stuttgart 1996.

Ders.: Die vorgetäuschte Integration. Die Auswirkungen der Bodenreform und Flüchtlingssiedlung auf die berufliche Eingliederung von Vertriebenen in die Landwirtschaft in Deutschland 1945-1960, in: Geglückte Integration? Spezifika und Vergleichbarkeiten der Vertriebenen-Eingliederung in der SBZ/DDR, hrsg. von Dierk Hoffmann und Michael Schwartz, München 1999, S. 193-214.

Ders.: Aufwertung und Nivellierung. Landarbeiter und Agrarpolitik in der SBZ/DDR 19451960, in: Peter Hübner/Klaus Tenfelde (Hrsg.): Arbeiter in der SBZ/DDR, Essen 1999, S. 245-267.

Ders./Sabrow, Martin/Stöver, Bernd (Hrsg.): Doppelte Zeitgeschichte. Deutsch-deutsche Beziehungen 1945-1990, Bonn 1998.

Belwe, Katharina: Zu den Hintergründen der Fluktuation in der DDR, in: DA 13 (1980), S. 601-611.

Dies.: Die Fluktuation Werktätiger als Ausdruck sozialer Konflikte in der DDR, Bonn 1982.

Dies.: Probleme der Arbeitskräftefreisetzung in der DDR, Bonn 1984.

Dies.: „Weniger produzieren mehr". Probleme der Freisetzung von Arbeitskräften in der DDR, in: DA 17 (1984), S. 496-509.

Dies.: Migration in der DDR. Landflucht und Verstädterung, in: DA 20 (1987), S. 515-530.

Bender, Gerd: Arbeitsvermittlung und Arbeitslosenversorgung in der Weimarer Republik. Ein sozialrechtshistorischer Überblick, in: Arbeitsvermittlung und Arbeitslosenversorgung in der neueren deutschen Rechtsgeschichte, hrsg. von Hans-Peter Benöhr, Tübingen 1991, S. 137-169.

Benz, Wolfgang: Vom Freiwilligen Arbeitsdienst zur Arbeitsdienstpflicht, in: VfZ 16 (1968), S. 317-346.

Ders.: Potsdam 1945. Besatzungsherrschaft und Neuaufbau im Vier-Zonen-Deutschland, Frankfurt am Main 1986.

Berghoff, Hartmut (Hrsg.): Konsumpolitik. Die Regulierung des privaten Verbrauchs im 20. Jahrhundert, Göttingen 1999.

Bessel, Richard: Germany after the First World War, Oxford 1993.

Ders./Jessen, Ralph (Hrsg.): Die Grenzen der Diktatur. Staat und Gesellschaft in der DDR, Göttingen 1996.

Die Bevölkerungsbilanz der sowjetischen Besatzungszone 1939 bis 1954, hrsg. vom Bundesministerium für gesamtdeutsche Fragen, Bonn 1954.

Bilanz der Arbeitskräfte und Arbeitsmarktlage in der Sowjetischen Besatzungszone, insbesondere in den Jahren 1949 und 1950, Bonn/Berlin 1951.

Blücher, Viggo Graf: Industriearbeiterschaft in der Sowjetzone. Eine Untersuchung der Arbeiterschaft in der volkseigenen Industrie der SBZ, Stuttgart 1959.

Boldorf, Marcel: Eingliederung der Kriegsopfer und Schwerbeschädigten Ostdeutschlands in den Arbeitsprozeß 1945-1951, in: Christoph Buchheim (Hrsg.): Wirtschaftliche Folgelasten des Krieges in der SBZ/DDR, Baden-Baden 1995, S. 403-415.

Ders.: Sozialfürsorge in der SBZ/DDR 1945-1953. Ursachen, Ausmaß und Bewältigung der Nachkriegsarmut, Stuttgart 1998.

Ders.: Fürsorgeunterstützung in Deutschland unter dem Einfluß der Zwangsmigrationen der Nachkriegszeit (1945-1952), in: Geglückte Integration? Spezifika und Vergleichbar- 
keiten der Vertriebenen-Eingliederung in der SBZ/DDR, hrsg. von Dierk Hoffmann und Michael Schwartz, München 1999, S. 233-246.

Borchardt, Knut: Wirtschaftliches Wachstum und Wechsellagen 1914-1970, in: Hermann Aubin/Wolfgang Zorn (Hrsg.): Handbuch der deutschen Wirtschafts- und Sozialgeschichte, Bd. 2, Stuttgart 1976, S. 198-275.

Ders.: Trend, Zyklus, Strukturbrüche, Zufälle: Was bestimmt die deutsche Wirtschaftsgeschichte des 20. Jahrhunderts?, in: VSWG 64 (1977), S. 145-178.

Ders.: Zwangslagen und Handlungsspielräume in der großen Weltwirtschaftskrise der frühen dreißiger Jahre: Zur Revision des überlieferten Geschichtsbildes, in: ders. (Hrsg.): Wachstum, Krisen, Handlungsspielräume der Wirtschaftspolitik. Studien zur Wirtschaftsgeschichte des 19. und 20. Jahrhunderts, Göttingen 1982, S. 165-182.

Bouvier, Beatrix: Ausgeschaltet! Sozialdemokraten in der Sowjetischen Besatzungszone und in der DDR 1945-1953, Bonn 1996.

Dies.: Forschungen zur DDR-Geschichte. Aspekte ihrer Konjunktur und Unübersichtlichkeit, in: AfS 38 (1998), S. 555-590.

Boyer, Christoph: Zwischen Zwangswirtschaft und Gewerbefreiheit. Handwerk in Bayern 1945-1949, München 1992.

Ders.: „Die Kader entscheiden alles ... " Kaderpolitik und Kaderentwicklung in der zentralen Staatsverwaltung der SBZ und der frühen DDR (1945-1952), Dresden 1996.

Ders./Skyba, Peter (Hrsg.): Repression und Wohlstandsversprechen. Zur Stabilisierung von Parteiherrschaft in der DDR und der ČSSR, Dresden 1999.

Ders./Skyba, Peter: Sozial- und Konsumpolitik als Stabilisierungsstrategie. Zur Genese der "Einheit von Wirtschafts- und Sozialpolitik“ in der DDR, in: DA 32 (1999), S. 577-590.

Braun, Jutta: Die Zentrale Kommission für Staatliche Kontrolle 1948-1953 - Wirtschaftsstrafrecht und Enteignungspolitik, in: Jutta Braun/Nils Klawitter/Falco Werkentin: Die Hinterbühne politischer Strafjustiz in den frühen Jahren der SBZ/DDR, Berlin 1997, S. 623.

Brentzel, Marianne: Die Machtfrau. Hilde Benjamin 1902-1989, Berlin 1997.

Broszat, Martin: Der Staat Hitlers. Grundlegung und Entwicklung seiner inneren Verfassung, München 1969.

Buchheim, Christoph: Die Währungsreform 1948 in Westdeutschland, in: VfZ 36 (1988), S. 189-231.

Ders.: Die Wiedereingliederung Westdeutschlands in die Weltwirtschaft 1945-1958, München 1990.

Ders. (Hrsg.): Wirtschaftliche Folgelasten des Krieges in der SBZ/DDR, Baden-Baden 1995.

Ders.: Wirtschaftliche Folgen der Integration der DDR in den RGW, in: ders. (Hrsg.): Wirtschaftliche Folgelasten des Krieges in der SBZ/DDR, Baden-Baden 1995, S. 341-361.

Ders.: Kriegsfolgen und Wirtschaftswachstum in der SBZ/DDR, in: GG 25 (1999), S. 515529.

Buck, Hannsjörg F.: Technik der Wirtschaftslenkung in kommunistischen Staaten. Funktionsweise und Funktionsschwächen der Zentralplanwirtschaft sowjetischen Typs in der UdSSR, in Mitteldeutschland und in den osteuropäischen Ländern, 2 Bde., Coburg 1969.

Buddrus, Michael: Die Organisation „Dienst für Deutschland“. Arbeitsdienst und Militarisierung in der DDR, Weinheim-München 1994.

Bust-Bartels, Axel: Herrschaft und Widerstand in den DDR-Betrieben. Leistungsentlohnung, Arbeitsbedingungen, innerbetriebliche Konflikte und technologische Entwicklung, Frankfurt am Main 1980.

Cassel, Dieter (Hrsg.): Wirtschaftspolitik im Systemvergleich. Konzeption und Praxis der 
Wirtschaftspolitik in kapitalistischen und sozialistischen Wirtschaftssystemen, München 1984.

Castell, Adelheid zu: Die demographischen Konsequenzen des Ersten und Zweiten Weltkriegs für das Deutsche Reich, die Deutsche Demokratische Republik und die Bundesrepublik Deutschland, in: Zweiter Weltkrieg und sozialer Wandel. Achsenmächte und besetzte Länder, hrsg. von Waclaw Dlugoborski, Göttingen 1981, S. 117-137.

Ciesla, Burghard: Der Spezialistentransfer in die UdSSR und seine Auswirkungen in der SBZ und DDR, in: APUZ B 49/50 (1993), S. 24-31.

Ders.: „Intellektuelle Reparationen“ der SBZ an die alliierten Siegermächte? Begriffsgeschichte, Diskussionsaspekte und ein Fallbeispiel - Die deutsche Flugzeugindustrie 19451946, in: Christoph Buchheim (Hrsg.): Wirtschaftliche Folgelasten des Krieges in der SBZ/DDR, Baden-Baden 1995, S. 79-109.

Ders.: Hinter den Zahlen. Zur Wirtschaftsstatistik und Wirtschaftsberichterstattung in der DDR, in: Akten. Eingaben. Schaufenster. Die DDR und ihre Texte, hrsg. von Alf Lüdtke und Peter Becker, Berlin 1997, S. 39-55.

Connor, Ian: Die Integration der Flüchtlinge und Vertriebenen in den Arbeitsprozeß nach 1945, in: Jahrbuch für ostdeutsche Volkskunde 32 (1989), S. 185-205.

Creuzberger, Stefan: Die sowjetische Besatzungsmacht und das politische System der SBZ, Weimar/Köln/Wien 1996.

DDR-Handbuch. Hrsg. vom Bundesministerium für innerdeutsche Beziehungen. Wissenschaftliche Leitung: Hartmut Zimmermann unter Mitarbeit von Horst Ulrich und Michael Fehlauer, 3. überarb. u. erw. Aufl. Köln 1985.

Deutschland unter alliierter Besatzung 1945-1949/55. Ein Handbuch, hrsg. von Wolfgang Benz, Berlin 1999.

Diedrich, Torsten: „Dienst für Deutschland“. Eine Wehr- und Arbeitsorganisation für die Jugend der DDR, in: DA 27 (1994), S. 830-841.

Ders.: Aufrüstungsvorbereitung und -finanzierung in der SBZ/DDR in den Jahren 1948 bis 1953 und deren Rückwirkungen auf die Wirtschaft, in: Volksarmee schaffen - ohne Geschrei! Studien zu den Anfängen einer "verdeckten Aufrüstung“ in der SBZ/DDR 19471952. Im Auftrag des Militärgeschichtlichen Forschungsamtes hrsg. von Bruno Thoß, München 1994, S. 273-336.

Dietrich, Martina/Eichholtz, Dietrich: Soziale Umbrüche in Brandenburg 1943-1945, in: Brigitte Berlekamp/Werner Röhr (Hrsg.): Terror, Herrschaft und Alltag im Nationalsozialismus. Probleme einer Sozialgeschichte des deutschen Faschismus, Münster 1995, S. $123-161$.

Dlugoborski, Waclaw (Hrsg.): Zweiter Weltkrieg und sozialer Wandel. Achsenmächte und besetzte Länder, Göttingen 1981.

Dost, Axel: Arbeitsrecht, in: Uwe-Jens Heuer (Hrsg.): Die Rechtsordnung der DDR. Anspruch und Wirklichkeit, Baden-Baden 1995, S. 95-145.

Drexler, Alexander: Planwirtschaft in Westdeutschland 1945-1948. Eine Fallstudie über die Textilbewirtschaftung in der britischen und Bizone, Wiesbaden 1985.

Dudek, Peter: Erziehung durch Arbeit. Arbeitslagerbewegung und freiwilliger Arbeitsdienst 1920-1935, Opladen 1988.

Eckart, Karl: Die wirtschaftspolitische Bedeutung der Schwarzmetallurgie (=Eisen- und Stahlindustrie) in der DDR, in: Diktaturen in Europa im 20. Jahrhundert - der Fall DDR, hrsg. von Heiner Timmermann, Berlin 1996, S. 567-580.

Elsner, Eva-Maria/Elsner, Lothar: Ausländer und Ausländerpolitik in der DDR, Berlin 1992.

Engelmann, Roger: Diener zweier Herren. Das Verhältnis der Staatssicherheit zur SED und 
den sowjetischen Beratern 1950-1959, in: Staatspartei und Staatssicherheit. Zum Verhältnis von SED und MfS, hrsg. von Siegfried Suckut und Walter Süß, Berlin 1997, S. 51-72.

Engeln, Ralf: Die industriellen Beziehungen im Uranbergbau der SAG Wismut, in: Rainer Karlsch/Harm Schröter (Hrsg.): „Strahlende Vergangenheit“. Studien zur Geschichte des Uranbergbaus der Wismut, St. Katharinen 1996, S. 171-208.

Ders.: Betriebliche Arbeitsbeziehungen bei der AG Wismut und in der volkseigenen Industrie im Vergleich 1946-1953, in: Peter Hübner/Klaus Tenfelde (Hrsg): Arbeiter in der SBZ/DDR, Essen 1999, S. 393-411.

Erker, Paul: Ernährungskrise und Nachkriegsgesellschaft. Bauern und Arbeiterschaft in Bayern 1943-1953, Stuttgart 1990.

Ders.: Keine Sehnsucht nach der Ruhr. Grundzüge der Industrialisierung in Bayern 19001970, in: GG 17 (1991), S. 480-511.

Ders./Pierenkemper, Toni (Hrsg.): Deutsche Unternehmer zwischen Kriegswirtschaft und Wiederaufbau. Studien zur Erfahrungsbildung von Industrie-Eliten, München 1999.

Ernst, Anna-Sabine: „Die beste Prophylaxe ist der Sozialismus“. Ärzte und medizinische Hochschullehrer in der SBZ/DDR 1945-1961, Münster/New York/München/Berlin 1997.

Erobert oder befreit? Deutschland im internationalen Kräftefeld und die sowjetische Besatzungszone (1945/46), hrsg. von Hartmut Mehringer, Michael Schwartz und Hermann Wentker, München 1999.

Etzel, Matthias: Die Aufhebung von nationalsozialistischen Gesetzen durch den Alliierten Kontrollrat (1945-1948), Tübingen 1992.

Fässler, Peter E.: „Diversanten“ oder „Aktivisten“? Westarbeiter in der DDR (1949-1961), in: VfZ 49 (2001), S. 613-642.

Faust, Anselm: Arbeitsmarktpolitik in Deutschland: Die Entstehung der öffentlichen Arbeitsvermittlung 1890-1927, in: Toni Pierenkemper und Richard Tilly (Hrsg.): Historische Arbeitsmarktforschung. Entstehung, Entwicklung und Probleme der Vermarktung von Arbeitskraft, Göttingen 1982, S. 253-276.

Ders.: Arbeitsmarktpolitik im Deutschen Kaiserreich. Arbeitsvermittlung, Arbeitsbeschaffung und Arbeitslosenunterstützung 1890-1918, Stuttgart 1986.

Ders.: Arbeitsvermittlung und Arbeitslosenversorgung in Deutschland von der Mitte des 19. Jahrhunderts bis zum Ende des Kaiserreichs, in: Arbeitsvermittlung und Arbeitslosenversorgung in der neueren deutschen Rechtsgeschichte, hrsg. von Hans-Peter Benöhr, Tübingen 1991, S. 105-135.

Feldman, Gerald D.: Economic and Social Problems of the German Demobilization, 191819, in: Journal of Modern History 47 (1975), S. 1-23.

Ders.: Die Demobilmachung und die Sozialordnung der Zwischenkriegszeit in Europa, in: GG 9 (1983), S. 156-177.

Feth, Andrea: Hilde Benjamin - Eine Biographie, Berlin 1997.

Fichter, Michael: Aufbau und Neuordnung: Betriebsräte zwischen Klassensolidarität und Betriebsloyalität, in: Martin Broszat u. a. (Hrsg.): Von Stalingrad zur Währungsreform. Zur Sozialgeschichte des Umbruchs in Deutschland, München 1988, S. 469-549.

Fiedler, Martin: Betriebliche Sozialpolitik in der Zwischenkriegszeit. Wege der Interpretation und Probleme der Forschung im deutsch-französischen Vergleich, in: GG 22 (1996), S. 350-375.

Filtzer, Donald: Soviet Workers and Stalinist Industrialization. The formation of modern Soviet production relations, 1928-1941, London/Sydney 1986.

Ders.: Soviet Workers and De-Stalinization. The consolidation of the modern system of soviet production relations, 1953-1964, Cambridge Univ. Press 1992. 
Fisch, Jörg: Reparationen nach dem Zweiten Weltkrieg, München 1992.

Fitzpatrick, Sheila: Stalin's peasants. Resistance and survival in the Russian village after collectivization, Oxford University Press 1994.

Foitzik, Jan: Sowjetische Militäradministration in Deutschland (SMAD) 1945-1949. Struktur und Funktion, Berlin 1999.

Foschepoth, Josef: Potsdam und danach: Die Westmächte, Adenauer und die Vertriebenen, in: Wolfgang Benz (Hrsg.): Die Vertreibung der Deutschen aus dem Osten. Ursachen, Ereignisse, Folgen, Frankfurt am Main 1995 (aktualisierte Neuausgabe), S. 86-113.

Frei, Norbert: Der Führerstaat. Nationalsozialistische Herrschaft 1933 bis 1945, München 1987.

Frerich, Johannes/Frey, Martin: Handbuch der Geschichte der Sozialpolitik in Deutschland, Bd. 2: Sozialpolitik in der Deutschen Demokratischen Republik, München 1993.

Frese, Matthias: Betriebspolitik im „Dritten Reich“. Deutsche Arbeitsfront, Unternehmer und Staatsbürokratie in der westdeutschen Großindustrie 1933-1939, Paderborn 1991.

Fricke, Karl Wilhelm: Politik und Justiz in der DDR. Zur Geschichte der politischen Verfolgung 1945-1968. Bericht und Dokumentation, Köln ${ }^{2} 1990$.

Fritz, Wolfgang: Die amtliche Erwerbstätigenstatistik in der DDR, in: Historical Social Research 22 (1997), S. 300-357.

Frölich, Jürgen (Hrsg.): „Bürgerliche“ Parteien in der SBZ/DDR. Zur Geschichte von CDU, LDP(D), DBD und NDPD 1945 bis 1953, Köln 1995.

Führer, Karl Christian: Arbeitslosigkeit und die Entstehung der Arbeitslosenversicherung in Deutschland 1902-1927, Berlin 1990.

Ders.: Mieter, Hausbesitzer, Staat und Wohnungsmarkt. Wohnungsmangel und Wohnungszwangswirtschaft in Deutschland 1914-1960, Stuttgart 1995.

Ganßmann, Heiner: Die nichtbeabsichtigten Folgen einer Wirtschaftsplanung. DDR-Zusammenbruch, Planungsparadox und Demokratie, in: Der Zusammenbruch der DDR. Soziologische Analyse, hrsg. von Hans Joas und Martin Kohli, Frankfurt a. M. 1993, S. 172-193.

Gayko, Axel: Die Industrialisierung des brandenburgischen Grenzraums an Oder und Neiße in den 50er und 60er Jahren. Bevölkerung und Arbeitsmarkt unter Berücksichtigung polnischer Grenzpendler, in: Peter Hübner/Klaus Tenfelde (Hrsg.): Arbeiter in der SBZ/ DDR, Essen 1999, S. 205-234.

Geyer, Martin H.: Die Reichsknappschaft. Versicherungsreformen und Sozialpolitik im Bergbau 1900-1945, München 1987.

Ders.: Soziale Sicherheit und wirtschaftlicher Fortschritt. Überlegungen zum Verhältnis von Arbeitsideologie und Sozialpolitik im „Dritten Reich“, in: GG 15 (1989), S. 382-406.

Gleitze, Bruno: Die Wirtschaftsstruktur der Sowjet-Zone und ihre gegenwärtigen sozialund wirtschaftsrechtlichen Tendenzen, Bonn 1951.

Ders.: Ostdeutsche Wirtschaft. Industrielle Standorte und volkswirtschaftliche Kapazitäten des ungeteilten Deutschland, Berlin 1956.

Gries, Rainer: Die Rationengesellschaft. Versorgungskampf und Vergleichsmentalität: Leipzig, München und Köln nach dem Kriege, Münster 1991.

Grossbölting, Thomas: Zwischen ökonomischer Marginalisierung und SED-Bündnispolitik: das Handwerk in der Sowjetischen Besatzungszone, in: ZfG 48 (2000), S. 405-422.

Grünert, Holle: Beschäftigungssystem und Arbeitsmarkt in der DDR, Opladen 1997.

Gruner-Domić, Sandra: Zur Geschichte der Arbeitskräftemigration in die DDR. Die bilateralen Verträge zur Beschäftigung ausländischer Arbeiter (1961-1989), in: IWK 1996, S. 204-230.

Günther, Adalbert: Die Aktion „Industriearbeiter aufs Land!“. Maßnahmen der SED zur 
Behebung des Arbeitskräftemangels in der Landwirtschaft, in: SBZ-Archiv 5 (1954), S. $277 \mathrm{f}$.

Gutmann, Gernot/Klein, Werner: Herausbildungs- und Entwicklungsphasen der Planungs-, Lenkungs- und Kontrollmechanismen im Wirtschaftssystem, in: Materialien der EnqueteKommission „Aufarbeitung von Geschichte und Folgen der SED-Diktatur in Deutschland“, hrsg. vom Deutschen Bundestag, Bd. II/3, Baden-Baden/Frankfurt am Main 1995, S. 1579-1647.

Gutmann, Gernot/Buck, Hannsjörg F.: Die Zentralplanwirtschaft der DDR - Funktionsweise, Funktionsschwächen und Konkursbilanz, in: Am Ende des realen Sozialismus. Beiträge zu einer Bestandsaufnahme der DDR-Wirklichkeit in den 80er Jahren, hrsg. von Eberhard Kuhrt in Verbindung mit Hannsjörg F. Buck und Gunter Holzweißig im Auftrag des Bundesministeriums des Innern, Bd. 2, Opladen 1996, S. 7-51.

Hachtmann, Rüdiger: Industriearbeit im „Dritten Reich“. Untersuchungen zu den Lohnund Arbeitsbedingungen in Deutschland 1933-1945, Göttingen 1989.

Ders.: Arbeitsverfassung, in: Drei Wege deutscher Sozialstaatlichkeit. NS-Diktatur, Bundesrepublik und DDR im Vergleich, hrsg. von Hans Günter Hockerts, München 1998, S. $27-$ 54.

Hackenberg, Gerd R.: Wirtschaftlicher Wiederaufbau in Sachsen 1945-1949/50, Köln/Weimar/Wien 2000.

Haerendel, Ulrike: Berufliche Mobilität von Flüchtlingen im Nachkriegsbayern, Frankfurt am Main u. a. 1994.

Halder, Winfrid: „Prüfstein ... für die politische Lauterkeit der Führenden“? Der Volksentscheid zur "Enteignung der Kriegs- und Naziverbrecher" in Sachsen im Juni 1946, in: GG 25 (1999), S. 589-612.

Ders.: „Modell für Deutschland“. Wirtschaftspolitik in Sachsen 1945-1948, Paderborn/ München/Wien/Zürich 2001.

Harrison, Hope Millard: The bargaining power of weaker allies in bipolarity and crisis: The dynamics of Soviet-East German relations, 1953-1961, Ann Arbor 1993.

Harsch, Donna: Society, the State and Abortion in East Germany, 1950-1972, in: American Historical Review 102 (1997), S. 53-84.

Heidemeyer, Helge: Flucht und Zuwanderung aus der SBZ/DDR 1945/1949-1961. Die Flüchtlingspolitik der Bundesrepublik Deutschland bis zum Bau der Berliner Mauer, Düsseldorf 1994.

Ders.: Vertriebene als Sowjetzonenflüchtlinge, in: Vertriebene in Deutschland. Interdisziplinäre Ergebnisse und Forschungsperspektiven, hrsg. von Dierk Hoffmann, Marita Krauss und Michael Schwartz, München 2000, S. 237-249.

Heimann, Christian: Systembedingte Ursachen des Niedergangs der DDR-Wirtschaft. Das Beispiel der Textil- und Bekleidungsindustrie 1945-1989, Frankfurt am Main u.a. 1997.

Heimkehr 1948. Geschichte und Schicksale deutscher Kriegsgefangener, hrsg. von Annette Kaminsky, München 1998.

Heldmann, Philipp: Konsumpolitik in der DDR. Jugendmode in den sechziger Jahren, in: Hartmut Berghoff (Hrsg.): Konsumpolitik. Die Regulierung des privaten Verbrauchs im 20. Jahrhundert, Göttingen 1999, S. 135-158.

Helwig, Gisela: Zwischen Familie und Beruf. Die Stellung der Frau in beiden deutschen Staaten, Köln 1974.

Dies.: Am Rande der Gesellschaft. Alte und Behinderte in beiden deutschen Staaten, Köln 1980.

Dies.: Frau und Familie. Bundesrepublik Deutschland - DDR, (2. völlig überarb. Aufl.) Köln 1987. 
Henke, Klaus-Dietmar: Der Weg nach Potsdam - Die Alliierten und die Vertreibung, in: Wolfgang Benz (Hrsg.): Die Vertreibung der Deutschen aus dem Osten. Ursachen, Ereignisse, Folgen, (aktualisierte Neuausgabe) Frankfurt am Main 1995, S. 58-85.

Hentschel, Volker: Geschichte der deutschen Sozialpolitik 1880-1980. Soziale Sicherung und kollektives Arbeitsrecht, Frankfurt am Main 1983.

Ders.: Wirtschafts- und sozialhistorische Brüche und Kontinuitäten zwischen Weimarer Republik und Drittem Reich, in: Zeitschrift für Unternehmensgeschichte 28 (1983), S. 39-80.

Ders.: Ludwig Erhard. Ein Politikerleben, München 1996.

Herbert, Ulrich: Fremdarbeiter. Politik und Praxis des „Ausländer-Einsatzes“ in der Kriegswirtschaft des Dritten Reiches, Bonn ${ }^{2} 1986$.

Ders.: Arbeiterschaft im „Dritten Reich“. Zwischenbilanz und offene Fragen, in: GG 15 (1989), S. 320-360.

Herbst, Andreas/Ranke, Winfried/Winkler, Jürgen (Hrsg.): So funktionierte die DDR. 3 Bde., Reinbek bei Hamburg 1994.

Herbst, Ludolf: Die Krise des Nationalsozialistischen Regimes am Vorabend des Zweiten Weltkrieges und die forcierte Aufrüstung, in: VfZ 26 (1978), S. 347-392.

Ders.: Der Totale Krieg und die Ordnung der Wirtschaft. Die Kriegswirtschaft im Spannungsfeld von Politik, Ideologie und Propaganda 1939-1945, Stuttgart 1982.

Ders.: Die DDR und die wirtschaftliche Integration des Ostblocks in den sechziger Jahren, in: Christoph Buchheim (Hrsg.): Wirtschaftliche Folgelasten des Krieges in der SBZ/ DDR, Baden-Baden 1995, S. 363-380.

Heydemann, Günther/Beckmann, Christopher: Zwei Diktaturen in Deutschland. Möglichkeiten und Grenzen des historischen Diktaturenvergleichs, in: DA 30 (1997), S. 12-40.

Heyl, Friedrich von: Der innerdeutsche Handel mit Eisen und Stahl 1945-1972. Deutschdeutsche Beziehungen im Kalten Krieg, Köln/Weimar/Wien 1997.

Hildermeier, Manfred: Interpretationen des Stalinismus, in: HZ 264 (1997), S. 655-674.

Ders.: Geschichte der Sowjetunion 1917-1991. Entstehung und Niedergang des ersten sozialistischen Staates, München 1998.

Hockerts, Hans Günter: Sozialpolitische Entscheidungen im Nachkriegsdeutschland. Alliierte und deutsche Sozialversicherungspolitik 1945 bis 1957, Stuttgart 1980.

Ders.: Grundlinien und soziale Folgen der Sozialpolitik in der DDR, in: Hartmut Kaelble/ Jürgen Kocka/Hartmut Zwahr (Hrsg.): Sozialgeschichte der DDR, Stuttgart 1994, S. 519 544.

Ders.: Soziale Errungenschaften? Zum sozialpolitischen Legitimitätsanspruch der zweiten deutschen Diktatur, in: Jürgen Kocka/Hans-Jürgen Puhle/Klaus Tenfelde (Hrsg.): Von der Arbeiterbewegung zum modernen Sozialstaat. Festschrift für Gerhard A. Ritter zum 65. Geburtstag, München u.a. 1994, S. 790-804.

Ders.: Einführung, in: Drei Wege deutscher Sozialstaatlichkeit. NS-Diktatur, Bundesrepublik und DDR im Vergleich, hrsg. von Hans Günter Hockerts, München 1998, S. 7-25.

Hoffmann, Dierk: Sozialpolitische Neuordnung in der SBZ/DDR. Der Umbau der Sozialversicherung 1945-1956, München 1996.

Ders.: Vertriebenenintegration durch Arbeitsmarktlenkung? Zur Beschäftigungspolitik der SBZ/DDR (1945-1950), in: Geglückte Integration? Spezifika und Vergleichbarkeiten der Vertriebenen-Eingliederung in der SBZ/DDR, hrsg. von Dierk Hoffmann und Michael Schwartz, München 1999, S. 173-192.

Ders.: Der Weg in die Planwirtschaft. Arbeitskräftelenkung in der SBZ/DDR 1945-1961, in: DA 32 (1999), S. 209-223.

Ders.: Die Lenkung des Arbeitsmarktes in der SBZ/DDR 1945-1961. Phasen, Konzepte und 
Instrumente, in: Peter Hübner/Klaus Tenfelde (Hrsg.): Arbeiter in der SBZ/DDR, Essen 1999, S. 41-80.

Ders.: Arbeitsmarkt, Zweijahresplan und Wirtschaftsverwaltung. Die Auseinandersetzung über Kommunalisierung oder Zentralisierung der Arbeitsämter, in: Das letzte Jahr der SBZ. Politische Weichenstellungen und Kontinuitäten im Prozeß der Gründung der DDR, hrsg. von Dierk Hoffmann und Hermann Wentker, München 2000, S. 107-132.

Ders.: Binnenwanderung und Arbeitsmarkt. Beschäftigungspolitik unter dem Eindruck der Bevölkerungsverschiebung in Deutschland nach 1945, in: Vertriebene in Deutschland. Interdisziplinäre Ergebnisse und Forschungsperspektiven, hrsg. von Dierk Hoffmann, Marita Krauss und Michael Schwartz, München 2000, S. 219-235.

Ders.: Im Laboratorium der Planwirtschaft. Von der Arbeitseinweisung zur Arbeitskräftewerbung in der SBZ/DDR (1945-1961), in: VfZ 48 (2000), S. 631-666.

Ders.: Sozialistische Rentenreform? Die Debatte über die Verbesserung der Altersversorgung in der DDR 1956/57, in: Geschichte und Gegenwart der Rentenversicherung in Deutschland. Beiträge zur Entstehung, Entwicklung und vergleichenden Einordnung der Alterssicherung im Sozialstaat, hrsg. von Stefan Fisch und Ulrike Haerendel, Berlin 2000, S. 293-309.

Hoffmann, Heinz: Die Betriebe mit staatlicher Beteiligung im planwirtschaftlichen System der DDR 1956-1972, Stuttgart 1999.

Hoffmann, Julius: Jugendämter im Wandel. Zur staatlichen Kinder- und Jugendpolitik in der SBZ/DDR (1945-1950), in: Jahrbuch für zeitgeschichtliche Jugendforschung 1994/95, S. 40-57.

Hoffmann, Manfred: Wohnungspolitik der DDR - das Leistungs- und Interessenproblem, Düsseldorf 1972.

Ders.: Sozialistische Mietenpolitik in der DDR, in: Zeitschrift für die gesamte Staatswissenschaft 129 (1973), S. 246-291.

Hofmann, Werner: Die Arbeitsverfassung der Sowjetunion, Berlin (West) 1956.

Hohmann, Joachim S.: „Wenn Sie dies lesen, bin ich schon auf dem Weg in den Westen.“ „Republikflüchtige“ DDR-Lehrer in den Jahren 1949-1961, in: ZfG 45 (1997), S. 311-330.

Holzwarth, Klaus: Die Anfänge der zentralen Wirtschaftsplanung in der SBZ, in: Christoph Buchheim (Hrsg.): Wirtschaftliche Folgelasten des Krieges in der SBZ/DDR, Baden-Baden 1995, S. 247-269.

Hübner, Peter: Zum Kohle- und Energieprogramm der DDR 1957, in: ZfG 32 (1984), S. 195205.

Ders.: Sozialhistorische Aspekte der industriellen Standortproblematik in der DDR. Bemerkungen zu einem Beitrag von Jörg Roesler, in: ZfG 36 (1988), S. 41-50.

Ders.: Balance des Ungleichgewichts. Zum Verhältnis von Arbeiterinteressen und SEDHerrschaft, in: GG 19 (1993), S. 15-28.

Ders.: Konsens, Konflikt und Kompromiß. Soziale Arbeiterinteressen und Sozialpolitik in der SBZ/DDR 1945-1970, Berlin 1995.

Ders.: Arbeiter und sozialer Wandel im Niederlausitzer Braunkohlenrevier von den dreißiger Jahren bis Mitte der sechziger Jahre, in: Ders. (Hrsg.): Niederlausitzer Industriearbeiter 1935 bis 1970. Studien zur Sozialgeschichte, Berlin 1995, S. 23-59.

Ders./Tenfelde, Klaus (Hrsg.): Arbeiter in der SBZ-DDR, Essen 1999.

Hürtgen, Renate: Die „vergessene“ Demokratisierung. Die Rolle des FDGB in den DDRBetrieben der sechziger Jahre, in: DA 33 (2000), S. 50-59.

Hüttenberger, Peter: Nationalsozialistische Polikratie, in: GG 2 (1976), S. 417-442.

Ihme-Tuchel, Beate: Das „nördliche Dreieck“. Die Beziehungen zwischen der DDR, der Tschechoslowakei und Polen in den Jahren 1954 bis 1962, Köln 1994. 
Geglückte Integration? Spezifika und Vergleichbarkeiten der Vertriebenen-Eingliederung in der SBZ/DDR, hrsg. von Dierk Hoffmann und Michael Schwartz, München 1999.

Inventar der Befehle des Obersten Chefs der Sowjetischen Militäradministration in Deutschland (SMAD) 1945-1949. Offene Serie. Im Auftrag des Instituts für Zeitgeschichte zusammengestellt und bearbeitet von Jan Foitzik, München/New Providence/London/Paris 1995.

Jahn, Manfred: Zur sächsischen Spezifik der Aufnahme von vertriebenen Deutschen 1945 bis 1949. Das Fallbeispiel Uranbergbau, in: Geglückte Integration? Spezifika und Vergleichbarkeiten der Vertriebenen-Eingliederung in der SBZ/DDR, hrsg. von Dierk Hoffmann und Michael Schwartz, München 1999, S. 215-229.

Das letzte Jahr der SBZ. Politische Weichenstellungen und Kontinuitäten im Prozeß der Gründung der DDR, hrsg. von Dierk Hoffmann und Hermann Wentker, München 2000.

Jánossy, Franz (unter Mitarbeit von Maria Holló): Das Ende der Wirtschaftswunder. Erscheinung und Wesen der wirtschaftlichen Entwicklung, Frankfurt am Main 1969.

Jarausch, Konrad/Siegrist, Hannes (Hrsg.): Amerikanisierung und Sowjetisierung in Deutschland 1945-1970, Frankfurt am Main/New York 1997.

Jessen, Ralph: Akademische Elite und kommunistische Diktatur. Die ostdeutsche Hochschullehrerschaft in der Ulbricht-Ära, Göttingen 1999.

Jodl, Markus: Amboss oder Hammer? Otto Grotewohl. Eine politische Biographie, Berlin 1997.

Just, Regine: Zur Lösung des Umsiedlerproblems auf dem Gebiet der DDR 1945 bis Anfang der fünfziger Jahre, in: ZfG 35 (1987), S. 971-984.

Dies.: Die Integration der Umsiedler im Land Sachsen, in: Sächsische Heimatblätter 35 (1989), S. 145-174.

Kaelble, Hartmut/Kocka, Jürgen/Zwahr, Hartmut (Hrsg.): Sozialgeschichte der DDR, Stuttgart 1994.

Kaiser, Monika: Sowjetischer Einfluß auf die ostdeutsche Politik und Verwaltung 1945-1970, in: Konrad Jarausch/Hannes Siegrist (Hrsg.): Amerikanisierung und Sowjetisierung in Deutschland 1945-1970, Frankfurt am Main/New York 1997, S. 111-133.

Dies.: Machtwechsel von Ulbricht zu Honecker. Funktionsmechanismen der SED-Diktatur in Konfliktsituationen 1962 bis 1972, Berlin 1997.

Kaltenborn, Steff: Der Versuch zur Wiederbelebung des Gablonzer Kunsthandwerks im Land Thüringen - Utopie oder reale Möglichkeit?, in: Christoph Buch heim (Hrsg.): Wirtschaftliche Folgelasten des Krieges in der SBZ/DDR, Baden-Baden 1995, S. 383-402.

Dies.: Wohn- und Lebensverhältnisse von Vertriebenen 1948 in Thüringen, in: Geglückte Integration? Spezifika und Vergleichbarkeiten der Vertriebenen-Eingliederung in der SBZ/ DDR, hrsg. von Dierk Hoffmann und Michael Schwartz, München 1999, S. 273-287.

Karlsch, Rainer: Zur Industrialisierung industriearmer Gebiete. Anmerkungen zu den Diskussionsbeiträgen von Peter Hübner und Jörg Roesler, in: ZfG 38 (1990), S. 235-240.

Ders.: Allein bezahlt? Die Reparationsleistungen der SBZ/DDR 1945-53, Berlin 1993.

Ders.: Der Traum vom Öl - zu den Hintergründen der Erdölsuche in der DDR, in: VSWG 80 (1993), S. 63-87.

Ders.: „Ein Staat im Staate“. Der Uranbergbau der Wismut AG in Sachsen und Thüringen, in: APUZ B 49/50 (1993), S. 14-23.

Ders./Bähr, Johannes: Die Sowjetischen Aktiengesellschaften (SAG) in der SBZ/DDR. Bildung, Struktur und Probleme ihrer inneren Entwicklung, in: Karl Lauschke und Thomas Welskopp (Hrsg.): Mikropolitik im Unternehmen. Arbeitsbeziehungen und Machtstrukturen in industriellen Großbetrieben des 20. Jahrhunderts, Essen 1994, S. 214-255. 
Ders.: Der Aufbau der Uranindustrien in der SBZ/DDR und ČSR als Folge der sowjetischen „Uranlücke“, in: ZfG 44 (1996), S. 5-24.

Ders./Schröter, Harm (Hrsg.): „Strahlende Vergangenheit“. Studien zur Geschichte des Uranbergbaus der Wismut, St. Katharinen 1996.

Ders.: „Man hat den Beruf nicht gewollt, aber man hat ihn geliebt." Heimkehrer bei der Wismut AG, in: Heimkehr 1948. Geschichte und Schicksale deutscher Kriegsgefangener, hrsg. von Annette Kaminsky, München 1998, S. 255-273.

Ders./Zacharov, Vladimir V.: Ein GULag im Erzgebirge? Besatzer und Besiegte beim Aufbau der Wismut AG, in: DA 32 (1999), S. 15-34.

Kleßmann, Christoph: Die doppelte Staatsgründung. Deutsche Geschichte 1945-1955, Bonn 41986.

Ders.: Zwei Staaten, eine Nation. Deutsche Geschichte 1955-1970, Bonn 1988.

Ders.: Die stilisierte Klasse - Arbeiter und Arbeiterbewegung in der Entstehungsphase der DDR (1945 bis 1948), in: AfS 39 (1999), S. 19-71.

Kluge, Ulrich/Halder, Winfrid: Die befohlene Wirtschaftsordnung in Sachsen 1945/46, in: Jürgen Schneider und Wolfgang Harbrecht (Hrsg.): Wirtschaftsordnung und Wirtschaftspolitik in Deutschland (1933-1993), Stuttgart 1996, S. 91-138.

Kohli, Martin: Die DDR als Arbeitsgesellschaft? Arbeit, Lebenslauf und soziale Differenzierung, in: Hartmut Kaelble/Jürgen Kocka/Hartmut Zwahr (Hrsg.): Sozialgeschichte der DDR, Stuttgart 1994, S. 31-61.

Kopstein, Jeffrey: Chipping away at the State: Worker's Resistance and the Demise of East Germany, in: World Politics 48 (1996) 2, S. 391-423.

Ders.: The Politics of Economic Decline in East Germany, 1945-1989, Chapel Hill and London 1997.

Kornai, János: Economics of Shortage, 2 Bde., Amsterdam/New York/Oxford 1980.

Ders.: Das sozialistische System. Die politische Ökonomie des Kommunismus, Baden-Baden 1995.

Kotkin, Stephen: Magnetic Mountain. Stalinism as a Civilization, Univ. of California Press 1995.

Kowalczuk, Ilko-Sascha/Mitter, Armin/Wolle, Stefan (Hrsg.): Der Tag X-17. Juni 1953. Die „Innere Staatsgründung“ der DDR als Ergebnis der Krise 1952/54, Berlin 1995.

Kranig, Andreas: Lockung und Zwang. Zur Arbeitsverfassung im Dritten Reich, Stuttgart 1983.

Ders.: Nationalsozialistische Arbeitsmarkt- und Arbeitseinsatzpolitik, in: Arbeitsvermittlung und Arbeitslosenversorgung in der neueren deutschen Rechtsgeschichte, hrsg. von Hans-Peter Benöhr, Tübingen 1991, S. 171-216.

Krumbein, Wolfgang: Wirtschaftsteuerung in Westdeutschland 1945 bis 1949. Organisationsformen und Steuerungsmethoden am Beispiel der Eisen- und Stahlindustrie in der britischen/Bi-Zone, Stuttgart 1989.

Kühr, Rüdiger: Die Reparationspolitik der UdSSR und die Sowjetisierung des Verkehrswesens der SBZ. Eine Untersuchung der Entwicklung der Deutschen Reichsbahn 1945-1949, Bochum 1996.

Laufer, Jochen: Die UdSSR und die deutsche Währungsfrage 1944-1948, in: VfZ 46 (1998), S. 455-485.

Leinweber, Ralf: Das Recht auf Arbeit im Sozialismus. Die Herausbildung einer Politik des Rechts auf Arbeit in der SBZ/DDR 1945 bis 1961, Marburg 1983.

Lemke, Michael: Die Sowjetisierung der SBZ/DDR im ost-westlichen Spannungsfeld, in: APUZ B 6 (1997), S. 41-53. 
Lewek, Peter: Arbeitslosigkeit und Arbeitslosenversicherung in der Weimarer Republik 1918-1927, Stuttgart 1992.

Lindenberger, Thomas: Die Diktatur der Grenzen. Zur Einleitung, in: Ders. (Hrsg.): Herrschaft und Eigen-Sinn in der Diktatur. Studien zur Gesellschaftsgeschichte der DDR, Köln/Weimar/Wien 1999, S. 13-44.

Lohmann, Ulrich: Die Entwicklung des Sozialrechts in der DDR, Opladen 1996.

Loth, Wilfried: Stalins ungeliebtes Kind. Warum Moskau die DDR nicht wollte, Berlin 1994.

Ludz, Peter Christian (Hrsg.): Studien und Materialien zur Soziologie der DDR, Köln/Opladen 1964.

Ders.: Parteielite im Wandel. Funktionsaufbau, Sozialstruktur und Ideologie der SED-Führung. Eine empirisch-systematische Untersuchung, Köln/Opladen ${ }^{2} 1968$.

Lüttinger, Paul (unter Mitwirkung von Rita Rossmann): Integration der Vertriebenen. Eine empirische Analyse, Frankfurt am Main /New York 1989.

Mählert, Ulrich: Die Freie Deutsche Jugend 1945-1949. Von den „Antifaschistischen Jugendausschüssen “ zur SED-Massenorganisation: Die Erfassung der Jugend in der Sowjetischen Besatzungszone, Paderborn u.a. 1995.

Mai, Gunther: Der Alliierte Kontrollrat in Deutschland 1945-1948. Alliierte Einheit - deutsche Teilung?, München 1995.

Maier, Robert: Die Stachanov-Bewegung 1935-1938. Der Stachanovismus als tragendes und verschärfendes Moment der Stalinisierung der sowjetischen Gesellschaft, Stuttgart 1990.

Major, Patrick: Vor und nach dem 13. August 1961: Reaktionen der DDR-Bevölkerung auf den Bau der Berliner Mauer, in: AfS 39 (1999), S. 325-354.

Malycha, Andreas: Partei von Stalins Gnaden? Die Entwicklung der SED zur Partei neuen Typs in den Jahren 1946 bis 1950, Berlin 1996.

Ders.: Die SED. Geschichte ihrer Stalinisierung 1946-1953, Paderborn u. a. 2000.

Mampel, Siegfried: Beiträge zum Arbeitsrecht in der Sowjetischen Besatzungszone Deutschlands, Bonn/Berlin 1963.

Ders.: Die sozialistische Verfassung der Deutschen Demokratischen Republik. Kommentar, Frankfurt am Main 21982.

Marcon, Helmut: Arbeitsbeschaffungspolitik der Regierungen Papen und Schleicher. Grundsteinlegung für die Beschäftigungspolitik im Dritten Reich, Bern/Frankfurt am Main 1974.

Martin, Thomas: „Und nichts war uns geblieben“. Der Weg der Freitaler Stahl-Industrie GmbH zum Volkseigenen Betrieb (1945-1948), Stuttgart 1997.

Mason, Timothy W.: Zur Entstehung des Gesetzes zur Ordnung der nationalen Arbeit vom 20. Januar 1934: Ein Versuch über das Verhältnis "archaischer “ und „moderner" Momente in der neuesten deutschen Geschichte, in: Hans Mommsen u. a. (Hrsg.): Industrielles System und politische Entwicklung in der Weimarer Republik, Düsseldorf 1974, S. 322-351.

Ders.: Sozialpolitik im Dritten Reich. Arbeiterklasse und Volksgemeinschaft, Opladen 21978.

Matschke, Werner: Die industrielle Entwicklung in der Sowjetischen Besatzungszone Deutschlands (SBZ) von 1945 bis 1948, Berlin (West) 1988.

Mehls, Hartmut: Arbeiterwohnungsbau und Wohnerfahrungen in Hoyerswerda zwischen 1955 und 1965, in: Peter Hübner (Hrsg.): Niederlausitzer Industriearbeiter 1935 bis 1970. Studien zur Sozialgeschichte, Berlin 1995, S. 233-262.

Mehringer, Hartmut (Hrsg.): Von der SBZ zur DDR. Studien zum Herrschaftssystem in der Sowjetischen Besatzungszone und in der Deutschen Demokratischen Republik, München 1995.

Meinicke, Wolfgang: Zur Entnazifizierung in der sowjetischen Besatzungszone unter Be- 
rücksichtigung von Aspekten politischer und sozialer Veränderungen (1945 bis 1948), Diss. A, Berlin (Ost) 1983.

Ders.: Die Entnazifizierung in der sowjetischen Besatzungszone 1945 bis 1948, in: ZfG 32 (1984), S. 968-979.

Ders.: Flüchtlinge, Umgesiedelte, Vertriebene in der Sowjetischen Besatzungszone. Ein kurzer historischer Überblick, in: ders./Plato, Alexander von: Alte Heimat - neue Zeit. Flüchtlinge, Umgesiedelte, Vertriebene in der Sowjetischen Besatzungszone und in der DDR, Berlin 1991, S. 23-81.

Melis, Damian van: Entnazifizierung in Mecklenburg-Vorpommern. Herrschaft und Verwaltung 1945-1948, München 1999.

Melzer, Manfred: Anlagevermögen, Produktion und Beschäftigung der Industrie im Gebiet der DDR von 1936 bis 1978 sowie Schätzung des künftigen Angebotspotentials, Berlin 1980.

Merl, Stephan: Die Anfänge der Kollektivierung in der Sowjetunion. Übergang zur staatlichen Reglementierung der Produktions- und Marktbeziehungen im Dorf (1928-1930), Wiesbaden 1985.

Ders.: Bauern unter Stalin. Die Formierung des sowjetischen Kolchossystems 1930-1941, Berlin 1990.

Meuschel, Sigrid: Legitimation und Parteiherrschaft. Zum Paradox von Stabilität und Revolution in der DDR 1945-1989, Frankfurt am Main 1992.

Milward, Alan S.: Arbeitspolitik und Produktivität in der deutschen Kriegswirtschaft unter vergleichendem Aspekt, in: Kriegswirtschaft und Rüstung 1939-1945, hrsg. von Friedrich Forstmeier und Hans-Erich Volkmann, Düsseldorf 1977, S. 73-91.

Mitter, Armin/Wolle, Stefan: Untergang auf Raten. Unbekannte Kapitel der DDR-Geschichte, München 1993.

Mühlfriedel, Wolfgang/Wießner, Klaus: Die Geschichte der Industrie der DDR bis 1965, Berlin (Ost) 1989.

Müller, Rolf-Dieter/Ueberschär, Gerd R.: Kriegsende 1945. Die Zerstörung des Deutschen Reiches, Frankfurt am Main 1994.

Müller, Rolf-Dieter: Albert Speer und die Rüstungspolitik im Totalen Krieg, in: Das Deutsche Reich und der Zweite Weltkrieg, hrsg. vom Militärgeschichtlichen Forschungsamt, Bd. 5/2: Kriegsverwaltung, Wirtschaft und personelle Ressourcen 1942-1944/45, Stuttgart 1999, S. 275-773.

Muth, Wolfgang: Berufsausbildung in der Weimarer Republik, Stuttgart 1985.

Naimark, Norman M.: The Russians in Germany. A History of the Soviet Zone of Occupation, 1945-1949, Cambridge (Mass.)/London 1995.

Normdurchsetzung in osteuropäischen Nachkriegsgesellschaften (1944-1989). Einführung in die Rechtsentwicklung mit Quellendokumentation. Bd. 1: Sowjetische Besatzungszone in Deutschland - Deutsche Demokratische Republik (1945-1960), hrsg. von Heinz Mohnhaupt und Hans-Andreas Schönfeldt, Frankfurt am Main 1997.

North, Douglass C.: Institutionen, institutioneller Wandel und Wirtschaftsleistung, Tübingen 1992.

Nove, Alec: Das sowjetische Wirtschaftssystem, Baden-Baden 1980.

Oertzen, Christine von/Rietzschel, Almut: Das „Kuckucksei“ Teilzeitarbeit. Die Politik der Gewerkschaften im deutsch-deutschen Vergleich, in: Gunilla-Friederike Budde (Hrsg.): Frauen arbeiten. Weibliche Erwerbstätigkeit in Ost- und Westdeutschland nach 1945, Göttingen 1997, S. 212-251.

Oertzen, Christine von: Teizeitarbeit und die Lust am Zuverdienen. Geschlechterpolitik und gesellschaftlicher Wandel in Westdeutschland 1948-1969, Göttingen 1999. 
Overy, Richard J.: Die Mobilisierung der britischen Wirtschaft während des Zweiten Weltkrieges, in: Kriegswirtschaft und Rüstung 1939-1945, hrsg. von Friedrich Forstmeier und Hans-Erich Volkmann, Düsseldorf 1977, S. 287-313.

Ders.: „Blitzkriegswirtschaft“? Finanzpolitik, Lebensstandard und Arbeitseinsatz in Deutschland 1939-1942, in: VfZ 36 (1988), S. 379-435.

Paulmann, Johannes: Staat und Arbeitsmarkt in Großbritannien. Krise, Weltkrieg, Wiederaufbau, Göttingen/Zürich 1993.

Peter, Roland: Rüstungspolitik in Baden. Kriegswirtschaft und Arbeitseinsatz in einer Grenzregion im Zweiten Weltkrieg, München 1995.

Petzina, Dietmar: Autarkiepolitik im Dritten Reich. Der nationalsozialistische Vierjahresplan, Stuttgart 1968.

Ders.: Die Mobilisierung deutscher Arbeitskräfte vor und während des Zweiten Weltkrieges, in: VfZ (1970), S. 443-455.

Ders.: Soziale Lage der deutschen Arbeiter und Probleme des Arbeitseinsatzes während des Zweiten Weltkriegs, in: Zweiter Weltkrieg und sozialer Wandel. Achsenmächte und besetzte Länder, hrsg. von Waclaw Dlugoborski, Göttingen 1981, S. 65-86.

Pierenkemper, Toni: Historische Arbeitsmarktforschung. Vorüberlegungen zu einem Forschungsprogramm, in: Ders. und Richard Tilly (Hrsg.): Historische Arbeitsmarktforschung. Entstehung, Entwicklung und Probleme der Vermarktung von Arbeitskraft, Göttingen 1982, S. 9-36.

Pirker, Theo/Lepsius, Rainer M./Weinert, Rainer/Hertle, Hans-Hermann: Der Plan als Befehl und Fiktion. Wirtschaftsführung in der DDR. Gespräche und Analysen, Opladen 1995.

Podewin, Norbert: Walter Ulbricht. Eine neue Biographie, Berlin 1995.

Port, Andrew: When workers rumbled: the Wismut upheaval of August 1951 in East Germany, in: Social History 22 (1997), S. 145-173.

Ders.: The „Grumble Gesellschaft“. Industrial Defiance and Worker Protest in Early East Germany, in: Peter Hübner/Klaus Tenfelde (Hrsg.): Arbeiter in der SBZ/DDR, Essen 1999, S. 787-810.

Poutrus, Kirsten: Von den Massenvergewaltigungen zum Mutterschutzgesetz. Abtreibungspolitik und Abtreibungspraxis in Ostdeutschland, 1945-1950, in: Richard Bessel/Ralph Jessen (Hrsg.): Die Grenzen der Diktatur. Staat und Gesellschaft in der DDR, Göttingen 1996, S. 170-198.

Preller, Ludwig: Sozialpolitik in der Weimarer Republik, (ND der 1949 ersch. Ausg.) Düsseldorf 1978.

Prinz, Michael: Vom neuen Mittelstand zum Volksgenossen. Die Entwicklung des sozialen Status der Angestellten von der Weimarer Republik bis zum Ende der NS-Zeit, München 1986.

Pschyrembel, Willibald: Klinisches Wörterbuch mit klinischen Syndromen, Berlin/New York 2531977.

Rademacher, Horst: Die Arbeitskräfteressourcen unserer Gesellschaft und ihr rationeller Einsatz, in: Einheit 15 (1960), S. 51-64.

Raphael, Lutz: Experten im Sozialstaat, in: Drei Wege deutscher Sozialstaatlichkeit. NS-Diktatur, Bundesrepublik und DDR im Vergleich, hrsg. von Hans Günter Hockerts, München 1998, S. 231-258.

Recker, Marie-Luise: Nationalsozialistische Sozialpolitik im Zweiten Weltkrieg, München 1985.

Rexin, Manfred: Veränderungen der Berufs- und Beschäftigtenstruktur und Probleme der 
Arbeitskräftelenkung in der DDR, in: Studien und Materialien zur Soziologie der DDR, hrsg. von Peter Christian Ludz, Köln/Opladen 1964, S. 59-85.

Richter, Michael: Die Ost-CDU 1948-1952. Zwischen Widerstand und Gleichschaltung, Düsseldorf 1990.

Ritschl, Albrecht: Über die Höhe und Struktur der gesamtwirtschaftlichen Investitionen in Deutschland 1935-38, in: VSWG 79 (1992), S. 156-176.

Ders.: Aufstieg und Niedergang der Wirtschaft der DDR: Ein Zahlenbild 1945-1989, in: Jahrbuch für Wirtschaftsgeschichte 1995/2, S. 11-46.

Ders./Spoerer, Mark: Das Bruttosozialprodukt in Deutschland nach den amtlichen Volkseinkommens- und Sozialproduktsstatistiken 1901-1995, in: Jahrbuch für Wirtschaftsgeschichte 1997/2, S. 27-54.

Ritter, Gerhard A.: Der Sozialstaat. Entstehung und Entwicklung im internationalen Vergleich, 2. überarb. u. erheb. erw. Aufl. München 1991.

Ders.: Über Deutschland. Die Bundesrepublik in der deutschen Geschichte, München 1998.

Ritzschel, Almut: Frauenerwerbstätigkeit und Teilzeitarbeit in der DDR 1957 bis 1970, in: Potsdamer Bulletin für Zeithistorische Studien, Nr. 9 (April 1997), S. 34-42.

Röhr, Rita: Polnische Arbeitskräfte in der DDR 1960-1970, in: Peter Hübner/Klaus Tenfelde, (Hrsg.): Arbeiter in der SBZ/DDR, Essen 1999, S. 185-204.

Roeling, Rob: Arbeiter im Uranbergbau: Zwang, Verlockungen und soziale Umstände (1945-1952), in: Rainer Karlsch/Harm Schröter (Hrsg.): „Strahlende Vergangenheit“. Studien zur Geschichte des Uranbergbaus der Wismut, St. Katharinen 1996, S. 99-133.

Roesler, Jörg: Die Herausbildung der sozialistischen Planwirtschaft in der DDR. Aufgaben, Methoden und Ergebnisse der Wirtschaftsplanung in der zentralgeleiteten volkseigenen Industrie während der Übergangsperiode vom Kapitalismus zum Sozialismus, Berlin (Ost) 1978.

Ders./Schwärzel, Renate/Siedt, Veronika: Produktionswachstum und Effektivität in Industriezweigen der DDR 1950-1970, Berlin (Ost) 1983.

Ders./Siedt, Veronika/Elle, Michael: Wirtschaftswachstum in der Industrie der DDR 19451970, Berlin (Ost) 1986.

Ders.: Die Integration der Umsiedler in die Volkswirtschaft der DDR und die Entstehung der Umsiedler-Neubauern, Ms. o.O. [1986].

Ders.: Zum Strukturwandel in der Industrie der DDR während der fünfziger Jahre. Fakten und Überlegungen, in: ZfG 35 (1987), S. 138-149.

Ders.: Zur Industrialisierung des Nordens der DDR in den fünfziger Jahren, in: ZfG 36 (1988), S. 1011-1023.

Ders.: Die Haltung der ostdeutschen Parteien zur Planwirtschaft und Marktwirtschaft 19451949, in: Deutsche Studien 28 (1990), S. 360-377.

Ders.: Zwischen Plan und Markt. Die Wirtschaftsreform in der DDR zwischen 1963 und 1970, Berlin 1991.

Roseman, Mark: Recasting the Ruhr, 1945-1958. Manpower, Economic Recovery and Labour Relations, New York/Oxford 1992.

Roth, Heidi/Diedrich, Torsten: "Wir sind Kumpel - uns kann keiner." Der 17. Juni 1953 in der SAG-Wismut, in: Rainer Karlsch/Harm Schröter (Hrsg.): „Strahlende Vergangenheit". Studien zur Geschichte des Uranbergbaus der Wismut, St. Katharinen 1996, S. 228 259.

Rouette, Susanne: Sozialpolitik als Geschlechterpolitik. Die Regulierung der Frauenarbeit nach dem Ersten Weltkrieg, Frankfurt am Main/New York 1993.

Sachse, Carola/Siegel, Tilla/Spode, Hasso/Spohn, Wolfgang: Angst, Belohnung, Zucht und Ordnung. Herrschaftsmechanismen im Nationalsozialismus, Opladen 1982. 
Sachse, Carola: Ein „heißes Eisen“. Ost- und westdeutsche Debatten um den Hausarbeitstag, in: Gunilla-Friederike Budde (Hrsg.): Frauen arbeiten. Weibliche Erwerbstätigkeit in Ostund Westdeutschland nach 1945, Göttingen 1997, S. 252-285.

SBZ-Handbuch. Staatliche Verwaltungen, Parteien, gesellschaftliche Organisationen und ihre Führungskräfte in der Sowjetischen Besatzungszone Deutschlands 1945-1949. Im Auftrag des Arbeitsbereiches Geschichte und Politik der DDR an der Universität Mannheim und des Instituts für Zeitgeschichte München hrsg. von Martin Broszat und Hermann Weber, München 1990.

Schenk, Fritz: Magie der Planwirtschaft, Köln/Berlin 1960.

Ders.: Im Vorzimmer der Diktatur. 12 Jahre Pankow, Köln/Berlin 1962.

Scherstjanoi, Elke: „In 14 Tagen werden Sie vielleicht schon keinen Staat mehr haben“. Vladimir Semenov und der 17. Juni 1953, in: DA 31 (1998), S. 907-937.

Schildt, Axel: Wohnungspolitik, in: Drei Wege deutscher Sozialstaatlichkeit. NS-Diktatur, Bundesrepublik und DDR im Vergleich, hrsg. von Hans Günter Hockerts, München 1998, S. 151-189.

Schneider, Jürgen: Von der nationalsozialistischen Kriegswirtschaftsordnung zur sozialistischen Zentralplanung in der SBZ/DDR, in: Jürgen Schneider und Wolfgang Harbrecht (Hrsg.): Wirtschaftsordnung und Wirtschaftspolitik in Deutschland (1933-1993), Stuttgart 1996, S. 1-90.

Ders./Harbrecht, Wolfgang: Einführung: Wirtschaftspolitische Experimente im Laboratorium Kriegswirtschaft/Weimar/Drittes Reich (1914-48) und in Sowjetrußland (ab 1917), in: dies. (Hrsg.): Wirtschaftsordnung und Wirtschaftspolitik in Deutschland (1933-1993), Stuttgart 1996, S. VII-XLIII.

Schneider, Michael C.: Bildung für neue Eliten. Die Gründung der Arbeiter- und BauernFakultäten, Dresden 1998.

Schröder, Hans-Henning: Arbeiterschaft, Wirtschaftsführung und Parteibürokratie während der Neuen Ökonomischen Politik: Eine Sozialgeschichte der bolschewistischen Partei 1920-1928, Wiesbaden 1982.

Ders.: Industrialisierung und Parteibürokratie in der Sowjetunion. Ein sozialgeschichtlicher Versuch über die Anfangsphase des "Stalinismus" 1928-1934, Berlin 1988.

Schroeder, Klaus: Der SED-Staat. Geschichte und Strukturen der DDR, München 1998.

Schürer, Gerhard: Gewagt und verloren. Eine deutsche Biographie, Frankfurt/Oder 1996.

Schulz, Günther: Wiederaufbau in Deutschland. Die Wohnungsbaupolitik in den Westzonen und der Bundesrepublik 1945 bis 1957, Düsseldorf 1994.

Schwartz, Michael: Vom „Flüchtling“ zum Neubürger. Vertriebenenintegration als gesellschaftspolitisches Problem der deutschen Nachkriegsgesellschaften, in: Transroda. Deutsch-Polnisches Informationsbulletin, H. 10/11, April 1995, S. 26-39.

Ders.: Zwischen Zusammenbruch und Stalinisierung. Zur Ortsbestimmung der Zentralverwaltung für deutsche Umsiedler (ZVU) im politisch-administrativen System der SBZ, in: Hartmut Mehringer (Hrsg.): Von der SBZ zur DDR. Studien zum Herrschaftssystem in der Sowjetischen Besatzungszone und in der Deutschen Demokratischen Republik, München 1995, S. 43-96.

Ders.: Vertreibung und Vergangenheitspolitik. Ein Versuch über geteilte deutsche Nachkriegsidentitäten, in: DA 30 (1997), S. 177-195.

Ders.: Apparate und Kurswechsel. Zur institutionellen und personellen Dynamik von „Umsiedler"-Politik in der SBZ/DDR 1945-1953, in: Geglückte Integration? Spezifika und Vergleichbarkeiten der Vertriebenen-Eingliederung in der SBZ/DDR, hrsg. von Dierk Hoffmann und Michael Schwartz, München 1999, S. 105-135.

Ders.: Vertrieben in die Arbeiterschaft: „Umsiedler" als "Arbeiter“ in der SBZ/DDR 1945- 
1952, in: Peter Hübner/Klaus Tenfelde (Hrsg.): Arbeiter in der SBZ/DDR, Essen 1999, S. 81-128.

Ders.: „Ablenkungsmanöver der Reaktion“. Der verhinderte Lastenausgleich in der SBZ/ DDR, in: DA 32 (1999), S. 397-409.

Schwarz, Hans-Peter: Die Ära Adenauer. Gründerjahre der Republik 1949-1957, Stuttgart 1981.

Schwarzer, Doris: Arbeitsbeziehungen im Umbruch gesellschaftlicher Strukturen. Bundesrepublik Deutschland, DDR und neue Bundesländer im Vergleich, Stuttgart 1996.

Schwarzer, Oskar: Der Lebensstandard in der SBZ/DDR 1945-1989, in: Jahrbuch für Wirtschaftsgeschichte 1995/2, S. 119-146.

Ders.: „Die Währung der DDR beruht ... auf der gesunden Grundlage der sozialistischen Gesellschaftsordnung“. Wechselkurse zwischen Mark der DDR und D-Mark, in: Jürgen Schneider und Wolfgang Harbrecht (Hrsg.): Wirtschaftsordnung und Wirtschaftspolitik in Deutschland (1933-1993), Stuttgart 1996, S. 173-205.

Ders.: Sozialistische Zentralplanwirtschaft in der SBZ/DDR. Ergebnisse eines ordnungspolitischen Experiments (1945-1989), Stuttgart 1999.

Die SED. Geschichte - Organisation - Politik. Ein Handbuch, hrsg. von Andreas Herbst/ Gerd-Rüdiger Stephan/Jürgen Winkler, Berlin 1997.

Sengenberger, Werner: Arbeitsmarktstruktur. Ansätze zu einem Modell des segmentierten Arbeitsmarkts, Frankfurt am Main/München 1975.

Ders. (Hrsg.): Der gespaltene Arbeitsmarkt. Probleme der Arbeitsmarktsegmentation, Frankfurt am Main/New York 1978.

Seraphim, Peter-Heinz: Die Heimatvertriebenen in der Sowjetzone, Berlin 1954.

Siegel, Tilla: Leistung und Lohn in der nationalsozialistischen „Ordnung der Arbeit“, Opladen 1989.

Siegelbaum, Lewis H.: Stakhanovism and The Politics of Productivity in the USSR, 19351941, Cambridge Univ. Press 1988.

Silverman, Dan P.: Fantasy and Reality in Nazi Work-Creation Programs, 1933-1936, in: Journal of Modern History 65 (1993), S. 113-151.

Ders.: Hitler's Economy. Nazi Work Creation Programs, 1933-1936, Cambridge (Mass.)/ London 1998.

Skyba, Peter: Vom Hoffnungsträger zum Sicherheitsrisiko. Jugend in der DDR und Jugendpolitik der SED 1949-1961, Köln/Weimar/Wien 2000.

Slusser, Robert (Hrsg.): Soviet Economic Policy in Postwar Germany. A Collection of Papers by Former Soviet Officials, New York 1953.

Social Dimensions of Soviet Industrialization, edited by William G. Rosenberg and Lewis H. Siegelbaum, Bloomington and Indianapolis 1993.

Soldt, Rüdiger: Zum Beispiel Schwarze Pumpe: Arbeiterbrigaden in der DDR, in: GG 24 (1998), S. 88-109.

Sommer, Ulf: Die Liberal-Demokratische Partei Deutschlands. Eine Blockpartei unter der Führung der SED, Münster 1996.

Sowart, Ralph: Planwirtschaft und die „Torheit der Regierenden“. Die „Ökonomische Hauptaufgabe der DDR“ vom Juli 1958, in: Jahrbuch für Historische Kommunismusforschung 1999, S. 157-190.

Springer, Philipp: „Da konnt' ich mich dann so 'n bißchen entfalten. “ Die Volkssolidarität in der SBZ/DDR 1945-1969, Frankfurt am Main u. a. 1999.

Staritz, Dietrich: Zum Verhältnis von Planungssystem und Partizipation in der DDR, in: DA 11 (1978), S. 1049-1070. 
Ders.: Die Gründung der DDR. Von der sowjetischen Besatzungsherrschaft zum sozialistischen Staat, (3. überarbeitete und erweiterte Neuauflage) München 1995.

Ders.: Geschichte der DDR. Erweiterte Neuausgabe, Frankfurt am Main 1996.

Steiner, André: Zwischen Länderpartikularismus und Zentralismus. Zur Wirtschaftslenkung in der SBZ bis zur Bildung der Deutschen Wirtschaftskommission im Juni 1947, in: APUZ, B 49/50 (1993), S. 32-39.

Ders.: Sowjetische Berater in den zentralen wirtschaftsleitenden Instanzen der DDR in der zweiten Hälfte der fünfziger Jahre, in: Jahrbuch für Historische Kommunismusforschung 1993, S. 100-117.

Ders.: Wirtschaftliche Lenkungsverfahren in der Industrie der DDR Mitte der fünfziger Jahre. Resultate und Alternativen, in: Christoph Buchheim (Hrsg.): Wirtschaftliche Folgelasten des Krieges in der SBZ/DDR, Baden-Baden 1995, S. 271-293.

Ders.: Beständigkeit oder Wandel? Zur Entwicklung der Industriestruktur der DDR in den sechziger Jahren, in: Jahrbuch für Wirtschaftsgeschichte 1995/2, S. 101-118.

Ders.: Die DDR-Wirtschaftsreform der sechziger Jahre. Konflikt zwischen Effizienz- und Machtkalkül, Berlin 1999.

Ders.: Die Deutsche Wirtschaftskommission - ein ordnungspolitisches Machtinstrument?, in: Das letzte Jahr der SBZ. Politische Weichenstellungen und Kontinuitäten im Prozeß der Gründung der DDR, hrsg. von Dierk Hoffmann und Hermann Wentker, München 2000, S. 85-105.

Ders.: Startbedingungen, Wirtschaftssystem und Wachstum. Die Wirtschaftsgeschichte der DDR im Licht der Forschung der letzten zehn Jahre, in: Jahrbuch für Historische Kommunismusforschung 2000/2001, S. 447-472.

Steinert, Johannes-Dieter: Die große Flucht und die Jahre danach. Flüchtlinge und Vertriebene in den vier Besatzungszonen, in: Ende des Dritten Reiches - Ende des Zweiten Weltkriegs. Eine perspektivische Rückschau, hrsg. von Hans-Erich Volkmann, München 1995, S. 557-579.

Stiebitz, Karen: Heinz Such (1910-1976). Ein Jurist zwischen bürgerlicher Rechtsdogmatik und sozialistischer Rechtsgewinnung, Köln/Weimar/Wien 1999.

Stokes, Raymond G.: Autarky, Ideology, and Technological Lag: The Case of the East German Chemical Industry, 1945-1964, in: Central European History 28 (1995), S. 29-45.

Ders.: Chemie und chemische Industrie im Sozialismus, in: Naturwissenschaft und Technik in der DDR, hrsg. von Dieter Hoffmann und Kristie Macrakis, Berlin 1997, S. 283-296.

Ders.: In Search of the Socialist Artefact: Technology and Ideology in East Germany, 19451962, in: German History 15 (1997), S. 221-239.

Stolper, Wolfgang F. (with assistance of Karl W. Roskamp): The Structure of the East German Economy, Cambridge/Mass. 1960.

Suckut, Siegfried: Die Betriebsrätebewegung in der Sowjetisch Besetzten Zone Deutschlands (1945-48), Frankfurt am Main 1982.

Süß, Walter: Die Arbeiterklasse als Maschine. Ein industrie-soziologischer Beitrag zur Sozialgeschichte des aufkommenden Stalinismus, Wiesbaden 1985.

Sywottek, Arnold: Deutsche Volksdemokratie. Studien zur politischen Konzeption der KPD 1935-1946, Düsseldorf 1971.

Ders.: „Kriegswirtschaft“ und „demokratische Wirtschaft“. Zur Diskussion um die „Übergangsgesellschaft“ am Beispiel der SBZ 1945-1948, in: Dirk Stegmann/Bernd-Jürgen Wendt/Peter-Christian Witt (Hrsg.): Industrielle Gesellschaft und politisches System. Beiträge zur politischen Sozialgeschichte. Festschrift für Fritz Fischer zum 70. Geburtstag, Bonn 1978, S. 151-171.

Thalheim, Karl C.: Die Wirtschaft der Sowjetzone in Krise und Umbau, Berlin (West) 1964. 
Ther, Philipp: Deutsche und polnische Vertriebene. Gesellschaft und Vertriebenenpolitik in der SBZ/DDR und in Polen 1945-1956, Göttingen 1998.

Thiel, Wera: Arbeitsrecht in der DDR. Ein Überblick über die Rechtsentwicklung und der Versuch einer Wertung, Opladen 1997.

Tilly, Richard H.: Märkte - Mächte - Arbeit. Beiträge zur Arbeitsmarktforschung, in: Toni Pierenkemper und Richard H. Tilly (Hrsg.): Historische Arbeitsmarktforschung. Entstehung, Entwicklung und Probleme der Vermarktung von Arbeitskraft, Göttingen 1982, S. 277-288.

Vergleich von Bildung und Erziehung in der Bundesrepublik Deutschland und in der Deutschen Demokratischen Republik, wissenschaftliche Kommission unter Leitung von Oskar Anweiler, Köln 1990.

Die Vertreibung der Deutschen aus dem Osten. Ursachen, Ereignisse, Folgen, hrsg. von Wolfgang Benz, (aktualisierte Neuausgabe) Frankfurt am Main 1995.

Vertriebene in Deutschland. Interdisziplinäre Ergebnisse und Forschungsperspektiven, hrsg. von Dierk Hoffmann, Marita Krauss und Michael Schwartz, München 2000.

Wagner, Georg: Sozialstaat gegen Wohnungsnot. Wohnraumbewirtschaftung und sozialer Wohnungsbau im Bund und in Nordrhein-Westfalen 1950-1970, Paderborn 1995.

Weber, Hermann: Geschichte der DDR, München 21986.

Ders.: Die DDR 1945-1990, 3. überarb. u. erw. Aufl. München 2000.

Weber, Petra: Justiz und Diktatur. Justizverwaltung und politische Strafjustiz in Thüringen 1945-1961, München 2000.

Drei Wege deutscher Sozialstaatlichkeit. NS-Diktatur, Bundesrepublik und DDR im Vergleich, hrsg. von Hans Günter Hockerts, München 1998.

Welsh, Helga A.: Revolutionärer Wandel auf Befehl? Entnazifizierungs- und Personalpolitik in Thüringen und Sachsen (1945-1948), München 1989.

Dies.: „Antifaschistisch-demokratische Umwälzung“ und politische Säuberung in der sowjetischen Besatzungszone Deutschlands, in: Klaus-Dietmar Henke/Hans Woller (Hrsg.): Politische Säuberung in Europa. Die Abrechnung mit Faschismus und Kollaboration nach dem Zweiten Weltkrieg, München 1991, S. 84-107.

Welskopp, Thomas: Der Betrieb als soziales Handlungsfeld. Neuere Forschungsansätze in der Industrie- und Arbeitergeschichte, in: GG 22 (1996), S. 118-142.

Wentker, Hermann: Justiz in der SBZ/DDR 1945-1953. Transformation und Rolle ihrer zentralen Institutionen, München 2001.

Wenzel, Siegfried: Wirtschaftsplanung in der DDR. Struktur - Funktion - Defizite, Berlin 1992.

Ders.: Plan und Wirklichkeit. Zur DDR-Ökonomie. Dokumentation und Erinnerungen, St. Katharinen 1998.

Wenzke, Rüdiger: Auf dem Weg zur Kaderarmee. Aspekte der Rekrutierung, Sozialstruktur und personellen Entwicklung des entstehenden Militärs in der SBZ/DDR bis 1952/53, in: Volksarmee schaffen - ohne Geschrei! Studien zu den Anfängen einer „verdeckten Aufrüstung" in der SBZ/DDR 1947-1952. Im Auftrag des Militärgeschichtlichen Forschungsamtes hrsg. von Bruno Thoß, München 1994, S. 205-272.

Werner, Stefan: Wirtschaftsordnung und Wirtschaftsstrafrecht im Nationalsozialismus, Frankfurt am Main/Bern/New York/Paris 1991.

Werum, Stefan: „Wir sind die Illegalen!“ Zum Wandel der Funktionen und Organisationsstrukturen des Freien Deutschen Gewerkschaftsbundes 1948-1952/53, in: AfS 39 (1999), S. 73-121.

Wienert, Helmut: Die Stahlindustrie in der DDR, Berlin 1992.

Wille, Manfred: Entnazifizierung in der SBZ 1945-1948, Magdeburg 1993. 
Ders.: Die Industrie Sachsen-Anhalts im Spannungsfeld zwischen Neuaufbau, Besatzungsregime und gesellschaftlichen Umbrüchen 1945-1947, in: Christoph Buchheim (Hrsg.): Wirtschaftliche Folgelasten des Krieges in der SBZ/DDR, Baden-Baden 1995, S. 141-168.

Winkler, Dörte: Frauenarbeit im „Dritten Reich“, Hamburg 1977.

Wisotzky, Klaus: Der Ruhrbergbau am Vorabend des Zweiten Weltkriegs. Vorgeschichte, Entstehung und Auswirkung der „Verordnung zur Erhöhung der Förderleistung und des Leistungslohnes im Bergbau“" vom 2. März 1939, in: VfZ 30 (1982), S. 418-461.

Ders.: Der Ruhrbergbau im Dritten Reich. Studien zur Sozialpolitik im Ruhrbergbau und zum sozialen Verhalten der Bergleute in den Jahren 1933 bis 1939, Düsseldorf 1983.

Wolf, Herbert/Sattler, Friederike: Entwicklung und Struktur der Planwirtschaft der DDR, in: Materialien der Enquete-Kommission „Aufarbeitung von Geschichte und Folgen der SED-Diktatur in Deutschland“, hrsg. vom Deutschen Bundestag, Bd. II/4, Baden-Baden/ Frankfurt am Main 1995, S. 2889-2940.

Wolffsohn, Michael: Industrie und Handwerk im Konflikt mit staatlicher Wirtschaftspolitik? Studien zur Politik der Arbeitsbeschaffung in Deutschland 1930-1934, Berlin (West) 1977.

Woller, Hans: Gesellschaft und Politik in der amerikanischen Besatzungszone. Die Region Ansbach und Fürth, München 1986.

Wolsing, Theo: Untersuchungen zur Berufsausbildung im Dritten Reich, Kastellaune u.a. 1977.

Wulff, Birgit: Arbeitslosigkeit und Arbeitsbeschaffungsmaßnahmen in Hamburg 1933-1939. Eine Untersuchung zur nationalsozialistischen Wirtschafts- und Sozialpolitik, Frankfurt am Main/Bern/New York/Paris 1987.

Zank, Wolfgang: Wirtschaftsplanung und Bewirtschaftung in der Sowjetischen Besatzungszone - Besonderheiten und Parallelen im Vergleich zum westlichen Besatzungsgebiet, 1945-1949, in: VSWG 71 (1984), S. 485-504.

Ders.: Nur aus Ruinen auferstanden? - Das „Wirtschaftswunder DDR“ im Licht einiger theoretischer Erklärungsansätze, in: deutsche studien (1985), S. 327-347.

Ders.: Wirtschaft und Arbeit in Ostdeutschland 1945-1949. Probleme des Wiederaufbaus in der Sowjetischen Besatzungszone Deutschlands, München 1987.

Zatlin, Jonathan R.: Ausgaben und Eingaben. Das Petitionsrecht und der Untergang der DDR, in: ZfG 45 (1997), S. 902-917.

Zollitsch, Wolfgang: Arbeiter zwischen Weltwirtschaftskrise und Nationalsozialismus. Ein Beitrag zur Sozialgeschichte der Jahre 1928 bis 1936, Göttingen 1990.

Zschaler, Frank: Die Entwicklung einer zentralen Finanzverwaltung in der SBZ/DDR 19451949/50, in: Hartmut Mehringer (Hrsg.): Von der SBZ zur DDR. Studien zum Herrschaftssystem in der Sowjetischen Besatzungszone und in der Deutschen Demokratischen Republik, München 1995, S. 97-138.

Ders.: Die vergessene Währungsreform. Vorgeschichte, Durchführung und Ergebnisse der Geldumstellung in der SBZ 1948, in: VfZ 45 (1997), S. 191-223. 


\section{Personenverzeichnis}

Abelshauser, Werner 3,9

Ackermann, Anton 543

Albrecht, Willi 405

Alexandrow, Georgi G. 169

Ambré, K. 424

Andrejew 340

Appell, Georg 37

Arndt $388 \mathrm{f}$.

Baranjok 142

Becher, Johannes R. 470

Becker, Leopold 316

Belke, Rudolf 26f., 36

Benjamin, Hilde 477

Bergholz, Albert 155

Böttger, Horst 531, 533

Bogdanow 343

Bohlmann, Fritz 22

Brack, Gustav 21, 24, 26-35, 37-39, 42, 44f., $48,78,99-101,118,127,138,141,150$, $161,167 \mathrm{f} ., 182,219,231,237 \mathrm{f}$.

Bromme 534

Bukow, G. S. 288

Burmeister, Friedrich 97

Chomjakow, W. A. $288 \mathrm{f}$.

Chruschtschow, Nikita S. 1, 463, 465

Chwalczyk, Georg 210f., 221

Chwalek, Roman 263, 287-293, 295-299, 330f., 334-336, 340, 344-346, 374f., 386, $388,399,415,417-419$

Clay, Lucius D. 66

Dahrendorf, Gustav 154

Donau 31, 110, 266, 356

Dressel 495

Eggerath, Werner 331, 405

Ender 514

Engel, Rudolf 214

Erhard, Ludwig 3

Eucken, Walter 548

Fechner, Max 26, 165, 247, 277, 423
Formin 196

Friedensburg, Ferdinand 155,160

Friedrichs, Rudolf 18

Furmin 315

Georgino, Willi 296

Geyer, Fritz 375

Göring, Bernhard 27

Goschütz 495

Gregor, Kurt 432

Greif 364

Grobbel, Karl $283 \mathrm{f}$.

Grotewohl, Otto 27, 131, 165, 224, $277 \mathrm{f}$, $302 \mathrm{f} ., 305,337,340,344,370,374$ f., 382, 413, 434

Gundelach, Gustav 25, 28, 117

Hager, Kurt 514

Häuseler $238 \mathrm{f}$.

Hamacher, Walter 27

Harbrecht, Wolfgang 548

Hecker 414

Heinicke 452, 458-460, 488

Heinze, Hildegard 57, 137, 164, 354, 488, 494

Heisig 263, 295f., 339, 343, 370, 399, 410

Helm, Rolf (Rudolf) 29, 53, 83-85

Herm, Max 22, 26, 53, 157, 277, 321

Herwegen, Leo 64

Hübener, Erhard 25

Huth $323,329,351,358$

Iljuschin $58,77,97,132$

Jánossy, Franz 9

Jendretzky, Hans 13, 16, 27, 38

Karlsch, Rainer 152, 314

Kern, Käthe 290, 300f., 407 f.

Kögl, Rudolf 176

Kolesnitschenko, Iwan S. 119

Kolopkow 323

Kornai, János $7 f$., 537, 547

Kotow, F. 512

Kowal, Konstantin I. 181 
Kreil, Heinrich 44, 53, 72f., 96, 99, 101, 127, $163,290,292$

Krüger 46, 77, 151, 172, 296, 335

Kulischow 24 $370,374,382,472,499 f ., 513,546$

Remissow, J. T. 21, 93

Riedel 388

Lamin 30,89

Lampka, Erwin 98

Lange, Fritz 283, 334

Lehmann, Helmut 24, 26 f., 29, 37f., 40-42, $71,124,131,204$

Lehmann, Otto 388

Lesser 406

Rumpf, Willi 386

Rutkowski 23

Schaposchnikow, T. P. $\quad 54,72,75$

Schaum, Gustav 53, 86

Schmidt, Elli 301

Schneider, Jürgen 548

Leuschner, Bruno 16, $202 \mathrm{f}$., 205, 254, 260, $366,390,394,432,531 \mathrm{f}$.

Litke, Karl 150, 166, 191, 268, 283, 315, 318, $324 \mathrm{f} ., 327,329,333$

Lobedanz, Reinhold 357

Loch, Hans 381

Lukjantschenko, Grigori S. 75

Lust 330

Schön, Otto 335

Schukow, Georgi K. 18, 123, 183, 208

Schumilin 334

Schwob, Fritz H. 33, 55, 231, 238

Seidel 375

Selbmann, Fritz $116,197,236,239,277$, 298, 328, 349f., 368, 370, 372, 374, 378, 513

Serow 317

Siewert, Robert 343

Macher, Fritz $443,454,458,461,470,486-$ 488, 491, 493, 497, 505, 513 f., 517 f., 521523

Malter, Friedel 258, 289f., 363f., 368, 416, 421, 507

Malzew, Andrej M. 127, 328, 333

Masanow, P. 289

Matern, Jenny 26f., $32 \mathrm{f}$.

Mehlich 388

Merker, Paul 27, 33, 48, 204

Mewis, Karl 531-533

Michalewitsch 374

Mittag, Günter 532

Moltmann, Carl 24

Smoljakow 182

Sobottka, Gustav 155-157

Sokolowski, Wassili D. 165, 230

Starck, Alexander 277

Steidle, Luitpold 266, 273, 282, 284 f., 304, 413

Steinhoff, Karl 295

Stoph, Willi 277, 371

Strassenberger 388

Studzinski 74

Such, Heinz 477

Thiele, Wilhelm $222 \mathrm{f}$.

Tschesnow, Michael 217

Morenow, P. J. 18, 24, 35, 81, 103, 109, 148, $158,169,183$

Mühlberg 204

Müller, Günther 52

Tschujkow, Wassili I. 257, 275

Ulbricht, Walter 1, 26, 87, 116f., 124, 165, $177,204,257,275,282$ f., 297, 332-334, 340 f., 343, 363, 371, 374, 393 f., $400 f ., 419$,

Nasanow 295

Ostaptschuk 533

Paffrath, Horst 27

Paul, Rudolf 51

Perwuchin, Michail G. 533

Peschke, Paul 253, 273, 277 f., 280, 282 f., 302

Pieck, Wilhelm 165, 224f., 319, 339, 374, 400

Pöhls, Werner $284 \mathrm{f}$.

Ponomarenkow 328

Puschkin, Georgi M. 436

Verner, Paul 503

Wachnin 171

Warnke, Herbert 517

Wenzel 341

Wichterey 469

Wießner, Rudi 400, 419, 514, 518

Wittkowski, Margarete 277, 490

Wolkow 182

Zank, Wolfgang 9, 15, 107, 143, 209, 212

Ziller, Gerhart 115, 165, 299, 432 